\title{
Understanding driver anger and aggression: Attributional theory in the driving environment
}

\author{
Wickens, C. M., Wiesenthal, D. L., Flora, D. B., \& Flett, G. L. \\ Version Post-Print/Accepted Manuscript \\ Citation Wickens, C. M., Wiesenthal, D. L., Flora, D. B., \& Flett, G. L. (2011). \\ (published version) Understanding driver anger and aggression: Attributional theory in the \\ driving environment. Journal of Experimental Psychology: Applied, \\ 17(4), 354-370, doi: https://dx.doi.org/10.1037/a0025815.
}

Publisher's Statement This article may not exactly replicate the authoritative document published in the APA journal. It is not the copy of record.

\section{How to cite TSpace items}

Always cite the published version, so the author(s) will receive recognition through services that track citation counts, e.g. Scopus. If you need to cite the page number of the TSpace version (original manuscript or accepted manuscript) because you cannot access the published version, then cite the TSpace version in addition to the published version using the permanent URI (handle) found on the record page. 
Running head: ATTRIBUTIONAL THEORY IN THE DRIVING ENVIRONMENT

Understanding Driver Anger and Aggression: Attributional Theory in the Driving Environment Christine M. Wickens, David L. Wiesenthal, David B. Flora, \& Gordon L. Flett York University

Author Note

Christine M. Wickens, David L. Wiesenthal, David B. Flora, Gordon L. Flett, Department of Psychology, York University.

Christine M. Wickens is now at the Social and Epidemiological Research Department, Centre for Addiction and Mental Health.

This research was supported by an Ontario Graduate Scholarship, a Social Sciences and Humanities Research Council of Canada Doctoral Fellowship, and a Canadian Transportation Research Forum Student Scholarship awarded to Dr. Wickens. This manuscript is based on research conducted by Dr. Wickens in partial fulfillment of the $\mathrm{PhD}$ requirements of York University. The authors wish to thank Professor C. Ward Struthers whose guidance in the development of the research contributed significantly to its success. The authors would also like to thank Amanda Near and Anabel Maldonado for their assistance with data entry.

Correspondence concerning this article should be addressed to Christine M. Wickens, Centre for Addiction and Mental Health, 33 Russell Street, Toronto, Ontario, M5S 2S1, Canada. Email: christine_wickens@camh.net 


\begin{abstract}
Two studies tested the applicability of Weiner's $(1995,1996,2001,2006)$ attributional model of social conduct to roadway environments. This model highlights the role of inferences of responsibility after making causal judgments for social transgressions. Study 1 employed written scenarios where participants were asked to imagine themselves driving on a major highway. The degree of controllability and intentionality of the driving act was manipulated experimentally by altering the specific event-related details provided to the participants. Study 2 extended this research to life events by having participants complete on-line driving diaries every 2 days, identifying their most negative/upsetting encounter with another motorist. The most angerprovoking event was selected from among 4 diary entries and participants were asked to respond to a questionnaire similar to that used in Study 1. Path analyses in both studies generally supported predictions derived from Weiner's model; the association between perceived controllability, intentionality, and dispositional locus of causality of the negative driving event and subsequent anger was mediated by perceptions of responsibility. Additional results in Study 2 suggested that low perceived controllability, intentionality, and dispositional locus of causality were associated with reduced perceived responsibility, which, in turn, facilitated feelings of sympathy. Anger was associated with aggressive responses to the offending driver, whereas sympathy was associated with prosocial responses. Recommendations were offered for improved driver safety, including the development of attributional retraining programs to combat selfserving attributional biases, teaching novice drivers about both formal and informal roadway communication, and the promotion of forgiveness among drivers.
\end{abstract}




\section{Understanding Driver Anger and Aggression:}

Attributional Theory in the Driving Environment

One of the primary contributing factors to motor vehicle collisions is aggressive driving behavior (Lawton, Parker, Stradling, \& Manstead, 1997; Wells-Parker et al., 2002), which includes various dangerous driving actions such as tailgating, cutting off other vehicles, and speeding. According to statements given at the U.S. Congress at a hearing of the Committee on Transportation and Infrastructure in 1997, aggressive driving was estimated to be involved in $50 \%$ of all motor vehicle collisions (Snyder, 1997), one third of all personal injuries, and two thirds of all fatalities resulting from motor vehicle crashes (Martinez, 1997).

Although factors internal to the aggressive driver have been found to contribute to aggressive driving behavior, including personality variables (Lajunen \& Parker, 2001; Lawton et al., 1997), mood (Arnett, Offer, \& Fine, 1997), and the experience of stress (Hennessy \& Wiesenthal, 1999, 2001), there is often a precipitating driving event that elicits aggressive behavior. Much aggressive driving displayed on the roadways is the result of driver anger and retaliation for a perceived driving offense (Hennessy \& Wiesenthal, 2002; Neighbors, Vietor, \& Knee, 2002; Parker, Lajunen, \& Summala, 2002; Wickens, Wiesenthal, Hall, \& Roseborough, 2011; Wickens, Wiesenthal, \& Rippey, 2005). Theories of attribution may provide some insight regarding aspects of driver behavior or the roadway environment that elicit aggression and minimize feelings of sympathy and compassion. Attributions emphasizing the responsibility of others and not the self play a role in anger and aggressive driving behaviors, which may be explained by Weiner's attribution model and its recent extension to social motivation and moral emotions reflecting sympathy for others (see Weiner, 1995, 1996, 2001, 2006). 
Theories of attribution depict the process by which individuals explain the events around them, traditionally focusing on perceived causality of behaviors and events (Fincham \& Jaspars, 1980). These theories have provided highly similar, yet distinct, explanations for the process of attribution (e.g., Heider, 1944, 1958; Jones \& Davis, 1966; Kelley, 1967). As these theories have developed, they have been extended to include subsequent emotions and behaviors resulting from specific attributions made (e.g., Feather, 1996, 1999; Fincham \& Roberts, 1985; Shaver, 1985; Shultz \& Darley, 1991). In an early application of attributional theory, Knapper and Cropley $(1978,1981)$ recognized that imputed inferences and perceptions about offensive drivers were primary determinants of affective and behavioral responses.

Feather and Deverson (2000) examined the impact of responsibility judgments on feelings related to punishment using written scenarios that manipulated elements of the driving context (the gender of the offending driver, the presence or absence of mitigating circumstances, and the moral worth of the offending motorist) but that ended with the same punishment. Participants' ratings of the offending motorist's responsibility for the punishment (and presumably for the collision) were related to ratings of the deservingness and perceived harshness of the penalty, which influenced affective reactions to the perpetrator.

Britt and Garrity (2006) asked drivers to recall when they had experienced specific angerprovoking events. The events included being tailgated, being cut off and forced to brake, and being stuck behind a slow driver in the passing lane. Participants then responded to questions regarding their attributions, emotions, and behaviors in response to each event. The attributional items were taken from Fincham and Bradbury’s (1992) model and included causal attributions of locus (the cause rests with something about the actor), stability (the cause for the actor's behavior is not likely to change in the future), and globality (the reason for the actor's behavior 
pervades across other areas of his or her life). Overall, Britt and Garrity (2006) found that stability was the most effective causal dimension as it significantly predicted anger and aggression in all driving scenarios. Locus and globality failed to predict anger or aggressive behavior in any of the scenarios. Blame attributions were important for both anger and aggression in the tailgating scenario. Hostile attributions played a role in the anger and aggression responses to the slow driver scenario and the anger response to the cut-off scenario. Taken as a whole, these results highlight the importance of attributional theory to the study of driver anger and aggression.

\section{The Current Study}

Thus far, researchers have focused on various components of these extended attributional models, including examinations of the operation of diverse variables determining causal attributions and judgments of responsibility (e.g., Arkkelin, Oakley, \& Mynatt, 1979; McKillip \& Posavac, 1975), how these causal attributions and responsibility judgments predict emotion (e.g., Britt \& Garrity, 2006; Feather \& Deverson, 2000) and aggressive behavior (e.g., Britt \& Garrity, 2006), and how anger is a necessary precursor to aggression (e.g., Neighbors et al., 2002; Nesbit, Conger, \& Conger, 2007; Parker et al., 2002). Yet there has been very little research that has assessed how all of these components function together in the context of driving. Application and assessment of a full attributional model to driver behavior would address this issue.

One attributional model that might be particularly relevant to the driving context is Weiner's $(1995,1996,2001,2006)$ attributional theory of social conduct, which is one of the most all-encompassing attributional models. The application of this model to social transgressions involves making an inference of responsibility after the transgressor has engaged 
in behavior that is perceived as reflecting internal and controllable causes stemming from the transgressor (see Weiner, 2001). Although Weiner's model has been applied to a wide variety of specific contexts, the general theory posits that attribution includes cognitive, affective, and behavioral components. The cognitive elements are described as determinants of affective responses, while affective responses are depicted as determinants of behavioral responses.

In the case of an individual who experiences a personal transgression, the victim will seek to determine the cause of that infraction. Within the cognitive stage of the process, the victim will assess various dimensions of the perceived cause of the transgression, forming the basis for a subsequent judgment or inference of the transgressor's responsibility for the harmful act (see Weiner, 2001). Responsibility, in turn, contributes to negative emotions such as feelings of anger. Although Weiner (2001) did not explicitly identify responsibility as a mediator, it is indicated clearly in this framework that the inference of responsibility follows attributional processing and judgments. As seen in Figure 1, Weiner (1979, 1985, 1995, 1996, 2001, 2006) has identified several causal dimensions including controllability, intentionality, locus of causality, stability, and globality. In applying the theory to a specific content domain, most researchers have focused on a subset of only two or three of these dimensions. Controllability of the event addresses whether the harmful act was under the transgressor's control or whether it was a preventable event. Intentionality speaks to whether or not the transgressor's actions were deliberate or inadvertent. Locus of causality reflects whether the harmful act was caused by something internal versus external to the transgressor. The stability dimension defines the cause as variant or invariant over time. Finally, the globality dimension is similar to stability; however, where stability examines temporal generalization, globality examines stimulus generalization. Using these dimensions, the victim will make a judgment of responsibility. Greater perceptions 
of controllability, intentionality, stability, and globality, and a stronger perception of internal or dispositional locus of causality, will lead the victim to judge the transgressor as responsible for the harmful act.

In the subsequent affective stage of the attribution process, a judgment of responsibility will evoke feelings of anger, whereas a judgment of minimal responsibility will evoke feelings of sympathy or concern for the transgressor (Weiner, 2001). In the behavior stage of the process, anger can motivate an aggressive reaction to the harmful act, whereas sympathy or concern can motivate prosocial behavior. In addition, Weiner's model has also been extended to include an inhibitory process whereby anger can inhibit prosocial behavior, and sympathy can inhibit aggressive behavior; however, this secondary process will not be assessed in the current study. Weiner's $(1995,1996,2001,2006)$ attributional model has been used to promote more positive emotional and behavioral reactions to interpersonal transgressions (Struthers, Dupuis, \& Eaton, 2005), victims of natural disasters (Marjanovic, Greenglass, Struthers, \& Faye, 2009), and stigmatized persons (Weiner, Perry, \& Magnusson, 1988). Yet despite its clear relevance, the model has seldom been examined in traffic psychology. A simpler version of this model that included only measures of intentionality, anger, and aggressive behavior was successfully applied to the driving context using a scenario-based self-report study (Vallières, Bergeron, \& Vallerand, 2005). This study did not examine other causal dimensions, the responsibility judgment, or positive emotions and behaviors, all of which are important components of Weiner's model. Even independently, some of these missing constructs may prove valuable in the study of driver behavior, yet they have been virtually ignored in the driving literature. For instance, although positive encounters may be less frequent in the roadway environment than negative encounters, or at least less frequently recalled due to an availability heuristic (Tversky 
\& Kahneman, 1974), the model could suggest ways to increase the frequency of positive roadway behavior.

To our knowledge, the current work represents the first attempt to apply Weiner's (1995, 1996, 2001, 2006) attributional model, in its entirety, to transgressions in driver behavior. Included in this research purpose was an assessment of perceived responsibility as a mediator of the relationship between causal attributions and driver emotions, which has not been investigated in the few previous studies of attributions and driving. The study also included an assessment of how attributional theory can account for positive emotions and behaviors in the driving context, which has also been neglected by prior applications of attributional theory to the roadway environment. Study 1 employed a laboratory-based methodology, whereas Study 2 used the recall of an anger-provoking situation experienced by a sample of drivers. It was hypothesized that the model could account for the various constructs, with the possible exception of the positive emotion and behavior components (see Figure 1).

\section{Study 1}

The use of fictional or hypothetical scenarios presented through either the printed word or audio playback has been the most commonly used method in driver-attribution research (e.g., Arkkelin et al., 1979; Feather \& Deverson, 2000; Vallières et al., 2005). Scenarios allow the maximum range of attributional, emotional, and behavioral responses to be studied. When initiating a new line of research, it is important to understand the range of possible responses before narrowing focus on any particular issue. Thus, the first study was designed to examine Weiner's model $(1995,1996,2001,2006)$ across all levels of causal attribution. A scenario was constructed involving a driver being cut off on the highway. The cutoff scenario was chosen since it has been identified as the most potentially anger-provoking driver offense (Britt \& 
Garrity, 2006; Wickens et al., 2005, 2011). Two of the five causal dimensions in Weiner's model (i.e., controllability and intentionality) were selected for experimental manipulation as a single study cannot examine all causal dimensions. In previous applications of Weiner's model, the dimensions of controllability and intentionality were the most frequently used across situational domains, and Weiner (2001) emphasized the role of intention and controllability judgments in determining responsibility for social transgressions. Although Weiner $(1995,1996)$ makes distinctions among the causal dimensions and provides examples when the presence of one dimension can occur in the absence of another, it is often common for these attributions to be positively correlated (Anderson, 1983), perhaps because it is difficult for perceivers to differentiate these concepts. Nonetheless, it is likely that a full range of scores in one causal dimension (e.g., controllability) will be reflected by a full range of scores in the other dimensions (e.g., locus of causality). These causal dimensions were manipulated by altering the situational information about the cutoff behavior.

All causal dimensions were expected to be positively correlated. Even in the case of controllability and intentionality, where the presence and absence of these dimensions were systematically controlled and fully balanced, a positive correlation was anticipated due to fine distinctions that might be difficult to make. More attributions of controllability, intentionality, stability, and globality, and a more person-focused locus of causality, were expected to be associated with stronger judgments of responsibility. Greater perceived responsibility was expected to predict more anger and less sympathy toward the driver. Anger was hypothesized to predict greater anticipated aggressive responding, and sympathy was expected to predict more anticipated prosocial responding. In addition, negative correlations between anger and sympathy and between aggressive and prosocial behavior were anticipated. 


\section{Method}

\section{Participants}

Participants were undergraduate students at a large, urban Canadian university. A total of 240 participants completed the study; however, two surveys were spoiled and 22 participants lacking driver's licenses were excluded. The remaining sample consisted of 64 men and 152 women. The mean age of participants was 22.10 years $(S D=4.07)$, and participants reported having possessed a driver's licence for a mean of 5.06 years $(S D=3.96)$ and driving a mean of 4.05 days per week $(S D=2.47)$.

\section{Measures and procedures}

A $2 \times 2$ (two levels of controllability by two levels of intentionality) between-subjects design was employed, where participants were asked to read a written driving scenario and to imagine themselves experiencing the situation. In each condition, the main story line was the same. Participants were asked to imagine that they were travelling in the center lane of a multilane highway. In their rearview mirror, and then their left side-view mirror, they notice another vehicle slowly overtaking them in the passing lane. When the vehicle finally overtakes them in the left lane, the driver of this vehicle suddenly pulls in front of them, cutting them off and forcing them to suddenly brake.

The situational context of this negative driving incident was experimentally manipulated to suggest the presence or absence of controllability and the presence or absence of intentionality. In a fully-crossed research design, participants were randomly assigned to one of four conditions (i.e., controllability - intentionality [C-I], controllability - no intentionality [C$\mathrm{NI}]$, no controllability - intentionality [NC-I], no controllability - no intentionality [NC-NI]). In the C-I condition, participants were told only that the other driver signalled once just as the 
vehicle pulled directly in front of them. In the C-NI condition, participants were told that there was a construction sign indicating that the left lane would end. Just as they both came over the crest of a hill, the left lane ended and the other driver suddenly pulled in front of them. In the NC-I condition, participants were told that they both came over the crest of a hill and suddenly a pothole was visible in the left lane. The other driver suddenly pulled directly in front of them. Finally, in the NC-NI condition, participants were told that the other vehicle's rear right tire suddenly blew out and the driver pulled directly in front of them.

After reading and imagining themselves in the assigned driving scenario, participants responded to questions regarding causal dimensions, judgment of responsibility, and anticipated emotions and behaviors. The causal dimensions included in the questionnaire were controllability, intentionality, locus of causality, stability, and globality. Controllability and intentionality items also served as a manipulation check. Anticipated emotions included anger and sympathy/concern, and the anticipated behaviors included aggressive behavioral responses and prosocial behavioral responses. All questionnaire items were designed specifically for the current study. Respondents rated each item on a 7-point scale. Labels for scale anchor points varied across the items. Given the exploratory nature of the research, aggressive behavior items incorporated a full range of possible aggressive driver responses, including more minor expressions (e.g., yelling at the other driver) as well as more extreme aggressive episodes (e.g., getting out of the vehicle ready to engage physically with the other driver). Previous research has tended to focus on less aggressive responding (e.g., Britt \& Garrity, 2006), as more extreme forms of aggression are rarely reported. 


\section{Results}

Exploratory factor analysis and reliability assessment

A series of exploratory factor analyses was conducted to explore the dimensional structure of the questionnaire. A limitation of this type of analysis is that it is data-driven as opposed to theory-driven, but this is a necessary and acceptable approach when developing a questionnaire for a novel line of research. The items were divided into manipulated and unmanipulated causal dimensions, causal judgment, emotions, and behaviors, as dictated by the proposed attributional model. Ordinary least squares estimation was used, and because factors were expected to be highly correlated, a promax rotation was applied.

Based on scree plots and parallel analyses, three of the factor analyses confirmed the hypothesized number of factors (i.e., two factors for manipulated causal dimensions [interfactor correlation $=.50 ;$ see Table 1], one factor for causal judgement [see Table 2], and two factors for emotions [interfactor correlation $=-.51$; see Table 3]). Focusing on the unmanipulated causal dimensions, the locus of causality, stability, and globality items all loaded onto the same factor. Given the important theoretical distinctions between them, the weaker stability and globality items were deleted from further analysis, which resulted in the emergence of a single factor (see Table 4). In terms of the behavioral items, the factor analysis identified distinctions between minor aggressive behaviors (e.g., yelling, gesturing), major aggressive behaviors (e.g., getting out of your vehicle to physically engage the other driver), and prosocial behaviors (e.g., offer assistance to the other driver if it is needed further down the road). The major aggressive behavior items were highly skewed and comprised most univariate outliers noted during the screening of the data. As most participants indicated minimal likelihood of engaging in these more extreme forms of aggressive responding, these items were eliminated from the analysis, 
leaving the less extreme aggressive behaviors and the prosocial behaviors (interfactor correlation $=-.21$; see Table 5). One of the prosocial behavior items (i.e., "How likely is it that you would gesture/signal to the other driver that everything is okay?") had a pattern coefficient of only .25. Although it could be argued that this low value might have warranted removing the item from the scale, it taps an important theoretical concept and was thus retained.

As expected, all bivariate correlations between factors were statistically significant $(p<$ .01 ) in the expected direction, ranging from -.22 to .79 (see Table 6). The internal consistency of the scales constructed based on the factor analysis was assessed using coefficient alpha. As seen in Table 6, a majority of reliability estimates were well above the recommended minimum of .70 for exploratory research (Nunnally \& Bernstein, 1994).

\section{Manipulation check}

Two two-way ANOVAs assessed the effectiveness of the experimental manipulation. The presence versus absence of control and intent served as the independent variables, while controllability scores and intentionality scores were dependent variables (see Figure 2).

The ANOVA of controllability scores revealed a significant main effect for the presence versus absence of control, $F(1,212)=116.89, p<.01, \eta^{2}=.36$, and a significant main effect for the presence versus absence of intent, $F(1,212)=10.27, p<.01, \eta^{2}=.05$. It also resulted in a significant interaction effect, $F(1,212)=7.30, p<.01, \eta^{2}=.03$. The ANOVA of intentionality scores revealed a significant main effect for the presence versus absence of intent, $F(1,212)=$ 28.41, $p<.01, \eta^{2}=.12$, and a significant main effect for the presence versus absence of control, $F(1,212)=33.07, p<.01, \eta^{2}=.14$. It also resulted in a significant interaction effect, $F(1,212)=$ $10.15, p<.01, \eta^{2}=.05$. The main effect of the presence or absence of control for the controllability scores and the main effect of the presence or absence of intent for the 
intentionality scores were consistent with predictions. The interaction effects were not unexpected, as these causal dimensions might be assumed by perceivers to co-occur, resulting in the presence of only one dimension producing attributions of the other dimension. For instance, in the absence of control, the NC-I group reported higher controllability scores than the NC-NI group (see Figure 2). However, when focusing on the intentionality scores, the NC-I group reported similar intentionality scores to both intent-absent groups (NC-NI and C-NI), suggesting that the NC-I manipulation may not have been successful in its implication of the presence of intent.

\section{Path Analysis}

Path analysis, a type of structural equation modeling that involves only observed variables, was used to allow simultaneous estimation of all hypothetical relationships in Weiner's $(1995,1996,2001,2006)$ model, which is more efficient than conducting a series of separate regression analyses and allows for comprehensive assessment of overall model fit (see Kline, 2005). Mardia's measure of multivariate kurtosis was 7.66, indicating moderate levels of non-normality (Mardia, 1970). Hence, the path analysis was conducted using maximum likelihood estimation with the Satorra-Bentler corrected model fit statistics and robust standard errors (Satorra \& Bentler, 1994, 2001) as implemented with Mplus 5.2. Only two cases with missing data were deleted listwise. The proposed model was estimated along with several direct paths that were expected to be mediated fully by one other variable in the model. For instance, anger was regressed onto controllability, locus of causality, and intentionality, although full mediation through responsibility was expected to make these paths nonsignificant. Nonsignificant paths not part of Weiner's model were deleted in a step-by-step fashion, 
proceeding from the smallest to the largest nonsignificant values. This systematic process allowed for more thorough testing of mediation and improved model parsimony.

With all direct paths included, the chi-square test for the initial model was significant, $\chi^{2}(8)=28.90, p<.01$; however, this test is overly sensitive to both correlation magnitude and sample size (Kline, 2005). The model fit was adequate based on the values of the CFI (.97) and the SRMR (.03), although the RMSEA (.11) was indicative of poor fit (e.g., MacCallum, Browne, \& Sugawara, 1996). For the final model with nonsignificant direct paths removed (see Figure 3, which includes standardized path estimates), the RMSEA (.10) improved slightly, indicating mediocre fit, whereas the other fit indices were virtually identical to the initial model, $\chi^{2}(11)=32.99, p<.01, \mathrm{CFI}=.96, \mathrm{SRMR}=.04$. The step-by-step deletion of nonsignificant paths mediated by one other variable led to the deletion of three direct paths; however, responsibility did not fully mediate the relationships between the causal dimensions of intentionality and locus of causality and anger, nor did responsibility fully mediate the relationship between the three causal dimensions and sympathy. Neither the hypothesized relationship between responsibility and sympathy nor the residual correlation between aggressive and prosocial behavior were significant. Because these non-significant paths were hypothesized relationships, they were retained in the final model.

In light of the finding that responsibility did not fully mediate the relationship between the causal dimensions of intentionality and locus of causality and the anger emotion, partial mediation was tested using the product of $z$-score approach in the Prodclin2 software (MacKinnon, Fritz, Williams, \& Lockwood, 2007). This method produces a 95\% confidence interval for the mediated effect, which indicates mediation at a .05 level of significance if the confidence interval does not include zero. Results of these mediation tests revealed that 
responsibility partially mediated the relationship between the causal dimensions of intentionality and locus of causality and the anger outcome. Responsibility did not mediate the relationship between any of the causal dimensions and the sympathy outcome.

Overall, squared multiple correlations $\left(R^{2}\right)$ indicated that the model accounted for $69 \%$ of the variance in responsibility, $44 \%$ of the variance in sympathy, $41 \%$ of the variance in anger, $40 \%$ of the variance in aggressive behavior, and $28 \%$ of the variance in prosocial behavior. Gender differences on the primary variables of interest were assessed, but none were found.

The model also could be estimated using the manipulated variables of controllability and intentionality (i.e., membership in the controllability vs. no-controllability group and membership in the intentionality vs. no-intentionality group); however, in light of the possibly unsuccessful manipulation of intentionality in the NC-I scenario, the path analysis using the continuous ratings of these constructs was preferred. The alternative model also fit the data well, $\chi^{2}(12)=19.48, p=.08, \mathrm{CFI}=.99, \mathrm{RMSEA}=.05, \mathrm{SRMR}=.04$, and was highly consistent with the Study 1 model, producing only a few differences. Specifically, the relationship between intentionality and responsibility was not significant (standardized path coefficient $b^{*}=.03, p=$ $.53)$. The relationship between responsibility and sympathy was significant $\left(b^{*}=-.23, p<.01\right)$, and responsibility partially mediated the relationship between both controllability and locus of causality and sympathy $\left(b^{*}=-.24, p<.01\right.$ and $b^{*}=-.28, p<.01$, respectively).

\section{Discussion}

Although the majority of factors and their relevant factor loadings were as expected, a few changes to the scales were required. The factor analysis of unmanipulated causal dimensions identified the need to remove stability and globality items from the analysis. Although clear theoretical distinctions between these constructs and locus of causality can be made, the 
statistical differences between the constructs within the current scenario were minimal. As previous research using these constructs has clearly demonstrated (Britt \& Garrity, 2006; Islam \& Hewstone, 1993; Weiner, Russell, \& Lerman, 1978), these causal dimensions and the distinctions between them are important to attributional theory. Still, not all types of attributions will be important in all situations. Britt and Garrity (2006) found that different types of causal attribution were more influential in certain types of driving offenses. In their assessment, hostile and blame attributions differentially predicted anger and aggression depending on the specific driving incident in question (tailgating, cut-off, or slow driver). Attributions of stability accounted for unique variance in all driving scenarios, whereas locus and globality attributions failed to account for any unique variance in any driving scenario.

It may be necessary for researchers to identify and focus on those attributional constructs that they think are most relevant to the topic of study. In driver psychology, it might be suggested that stability and globality are not particularly relevant, as they both address aspects of consistency. Stability addresses temporal consistency, asking whether the abusive motorist drives offensively all the time. Globality addresses situational consistency, asking whether the abusive motorist behaves offensively in other areas of his or her life. Yet we are unlikely to encounter an offensive driver on or off the road following the negative event. Thus, it may be more relevant to consider the dimensions of controllability, intentionality, and locus of causality. As well, globality may not be easily translated into a causal dimension that has explanatory power for the driving context. It may be that the perception of situational consistency is better conceptualized as a temperament or personality characteristic on the part of the victim driver, taking the form of pessimism, cynicism, or attributional style. 
Regardless of which causal dimensions are most relevant to the driving context, because they are all conceptually similar, it is likely that they account for common variance in driver anger and aggression. If controllability and intentionality had been included in Britt and Garrity's (2006) study, then perhaps stability would not have been such a strong predictor across all scenarios. The inclusion of intentionality might also have altered the amount of variance accounted for by hostile attributions. These considerations highlight the importance of basing empirical driving-related research on established attributional theory and giving serious thought to how each of its components might best be applied to driver psychology. As expected, the results of the exploratory factor analysis also indicated the need to eliminate the most extreme aggressive behavior items, as very few participants reported any anticipation of engaging in these behaviors, leading to strongly positively skewed distributions. Although exploratory factor analysis is a necessary method in developing a novel line of research, further study is needed to cross-validate exploratory scale construction.

The manipulation check confirmed that perceived controllability was greater in the control-present driving scenarios than in the control-absent driving scenarios, and that perceived intentionality was greater in the intention-present versus intention-absent scenarios. On the other hand, a comparison of the intentionality scores for the NC-I group to the intent-absent groups (NC-NI and C-NI) revealed no differences in perceived intentionality, suggesting that the manipulation may not have been entirely successful for that condition. It could be argued that the intentionality score for the NC-I group might be expected to be slightly less than the intentionality score of the C-I group, as the situation described in this scenario is more ambiguous. The fact that the intentionality score for the NC-I group did not differ from the NCNI group suggests a failure of the manipulation. Participants in the NC-I group read about an 
offending driver who drove over the crest of a hill and was suddenly faced with a pothole in the road. The driver chose to avoid the pothole by cutting off the participant in an adjacent lane. This scenario was designed to suggest the absence of controllability, as the appearance of the pothole over the crest of the hill was entirely unforeseeable and uncontrollable. Yet the scenario was also designed to suggest the presence of intent, as the driver's avoidance of the pothole by cutting off the participant was a conscious decision and he or she could have chosen to drive over the pothole instead. It seems that the participants in this study considered the offending motorist's avoidance of the pothole to be a necessary or reflexive action as opposed to a reasoned choice. They may also have considered the response of the offending driver to be one that they themselves would have made, which might have altered their attribution of intentionality. Nonetheless, the manipulation failure on this one cell in the ANOVA was not entirely ruinous, as there was still a wide range of scores on the intentionality scale.

The path analysis indicated that Weiner's (1995, 1996, 2001, 2006) model generally fit the data; however, a few revisions were necessary. As expected, controllability, intentionality, and locus of causality were positively related to responsibility. The strength of the relationship between intentionality and responsibility was not as strong as the relationship between the other two causal dimensions and responsibility, which may have been the result of the NC-I manipulation failure. As expected, anger was positively predicted by responsibility, but contrary to expectation, sympathy was not associated with perceptions of responsibility, in contrast to predictions outlined by Weiner. Responsibility was also expected to mediate fully the relationship between the causal dimensions and emotional responses, although only one such path was fully mediated. Specifically, responsibility fully mediated the relationship between controllability and anger. Intentionality and locus of causality were positively related to anger, 
and responsibility partially mediated this relationship. All three causal dimensions were negatively related to sympathy, controlling responsibility. As expected, aggressive behavior was positively predicted by anger and prosocial behavior was positively predicted by sympathy. The residuals of anger and sympathy were negatively correlated, but contrary to expectation, the residuals of aggressive and prosocial behavior were not correlated.

Although responsibility is a principal aspect of Weiner's $(1995,1996,2001)$ conceptualization of the relationship between attributions and aggressive behavior, others have questioned its central role (Feather \& Deverson, 2000). Driver behavior researchers have chosen not to study responsibility (e.g., Britt \& Garrity, 2006; Takaku, 2006; Vallières et al., 2005), treating the causal dimensions as components of, rather than antecedents of, the more encompassing inference of personal responsibility. The results of the current study suggest that responsibility as a separate cognitive process can play a meaningful role in the driving context, as the relationship between controllability and anger was fully mediated by responsibility. The finding that responsibility only partially mediated the relationship between the causal dimensions of intentionality and locus of causality, and the anger emotion, suggests that the intervening role of responsibility may not be absolute. The lack of a significant relationship between responsibility and sympathy, despite significant relationships between the three causal dimensions and both responsibility and sympathy, leads to further questioning of the role of causal judgment in the application of attributional theory to driving. Future research may demonstrate that the construct of responsibility is less necessary for the study of driver aggression, as the fast-paced roadway fails to provide sufficient opportunity to cognitively process an independent judgment of responsibility. It may be more appropriate to treat responsibility as an automatic implication of perceived causal dimensionality. Applications of 
Weiner's model to other contexts have used this approach, combining the causal dimensions and a responsibility inference within a single variable (e.g., Struthers, Eaton, Mendoza, Santelli, \& Shirvani, 2010; Greitemeyer, Rudolph, \& Weiner, 2003). Future research may also refine the more multifaceted construct of responsibility judgment used here and identify the feature most relevant to the driving context. Theoretical distinctions can be drawn between responsibility, blame, and deserved punishment (Weiner, 1995), which may influence the role of responsibility judgment in the driver's attributional process.

Study 2

Study 2 was designed to examine Weiner's (1995, 1996, 2001, 2006) model within the context of life events and experiences. Whereas Study 1 presented a hypothetical driving scenario, Study 2 asked participants to consider an anger-provoking event they had experienced. Britt and Garrity (2006) asked participants to recall specific driving events from their past, but it is possible that participants may not have been recalling details of the event but rather confabulating with stereotype-based information. Study 2 used a driving diary methodology to further evaluate the applicability of Weiner's model within the context of life experiences. Study 2 was deemed essential in order to examine the generalizability of the findings of Study 1 , as well as allow for the possibility that certain results from Study 1 (e.g., the lack of an association between perceived responsibility and sympathy) were due, at least in part, to the use of hypothetical scenarios rather than life experiences.

The nature of the negative driving events reported was expected to be very diverse and it was unclear how this diversity would impact the usefulness of the causal dimensions in the model. Applying the behavioral items from Study 1 - particularly the prosocial behavior items to Study 2 also posed several problems. These challenges necessitated testing a revised version 
of Weiner's $(1995,1996,2001,2006)$ model. This alternate model substituted thoughts about engaging in a particular behavior for the behaviors themselves.

\section{Method}

\section{Participants}

To take part in this research study, participants were required to have held a class G2 (the level of graduated licensing at which new drivers are permitted to drive independently) or G Ontario driver's license for at least 1 year, drive at least 4 days per week on average, and have Internet access from home. Fifty participants were recruited through advertisements posted across the university's main campus, and an additional 152 participants were recruited through an undergraduate participant pool; thus, 202 participants were assembled. Two respondents were eliminated for careless responding and 1 respondent was eliminated because he had previously participated in a similar study that might result in biased responding. The remaining sample consisted of 58 men and 141 women. The mean age of participants was 23.24 years $(S D=7.17)$, and participants reported having possessed a driver's licence for a mean of 6.04 years $(S D=$ 5.74).

\section{Measures and procedures}

Participants completed a total of four online driving diaries, once every 2 days. On the morning of the day that their diary entry was to be submitted, participants received an e-mail containing a link to the online diary which asked them to describe a negative driving event involving another motorist, experienced during the previous 2 days. They were asked to describe the nature of the event, where it took place, how the encounter made them feel, and what they did after or in response to the event. Participants rated the negativity and severity of the event and the extent to which they felt anger toward the other driver on a 7-point Likert-type scale. 
Participants were instructed that if they had not driven in the past 48 hours, or if they did not drive a sufficient distance to experience even a minor annoyance on the roadway, to submit their diary but respond with "not applicable" to all open-ended questions and with "1" to all scales. Participants who did not submit a diary entry received a prompting e-mail each morning.

After all four diaries had been submitted, respondents were sent another link for the final on-line survey which was focused on the most upsetting and negative driving event with the highest Likert-type rating of anger toward the other driver reported in the four diaries. If multiple entries had the same score on this scale, the rating of negativity of the event broke the tie. If multiple entries had identical scores for both anger and negativity, perceived severity of the event was used to break the tie.

Participants were instructed to write a short paragraph describing this upsetting event (i.e., what happened, how did you feel, what did you do). Participants were then asked to complete a questionnaire that was almost identical to the one presented to participants in Study 1. The items were revised so that they were not specific to being cut off by another motorist, but rather were applicable to any number of offensive driving behaviors. The behavioral items were altered so that they asked about behaviors committed rather than behavioral responses that drivers anticipated committing. Revisions to the three prosocial behavior items were not straightforward. Two of the items involved highly unlikely hypothetical events during the critical incident (i.e., offering personal assistance to the driver, calling police or a tow truck to assist the driver). The elimination of these items would have left only one item to measure prosocial behavior (i.e., gesturing to the other driver that everything is okay). In addition, not knowing in advance what types of events would be reported and what opportunities for aggression would 
emerge, it was difficult to determine how appropriate the aggressive behavior items would be in the current study.

In response to these limitations, two new sets of constructs were added to the questionnaire: aggressive thought (five items) and prosocial thought (three items). These constructs included the same types of behaviors as did Study 1 and asked what participants considered doing in response to the offending driver. Thus, aggressive and prosocial thought items generally used the phrasing "To what extent did you THINK ABOUT...?”, whereas the aggressive and prosocial behavior items used the phrasing “To what extent DID you...?”. An exception to this phrasing was made to two of the three prosocial thought items, which retained the same format as the prosocial behavior items in Study 1. These items involved hypothetical events that would not likely be spontaneously considered by participants in the driving environment.

\section{Results}

\section{Diary entries}

For the first diary entry, nine participants indicated that they had not encountered a negative driving event involving another motorist. For the second, third, and fourth diary entries, 13, 42, and 35 participants, respectively, reported not experiencing a negative driving event. Thus, a majority of drivers encountered at least one negative event involving another motorist within a 48-hr period. Across all four diary entries, an average of $88 \%$ of participants reported at least a minor anger-provoking event within that time frame.

\section{Post diary survey}

Only two participants described a critical incident not included in one of the four diary entries. One of these participants noted that the critical event took place on the morning that the 
participant received the link for the final survey. Five participants ignored instructions and focused on driving altercations involving multiple vehicles, and two participants focused on driving altercations involving atypical vehicles (e.g., bus, tractor trailer); they were nonetheless retained in the analysis as there were few of them. The mean level of anger felt toward the other driver in the critical incident was $5.45(S D=1.49)$. For approximately $76 \%$ of the sample, their reported anger toward the other driver was ranked 5 or higher on the 7-point scale. The mean perceived negativity of the critical incident was $5.27(S D=1.43)$ and the mean perceived severity was $4.37(S D=1.78)$. The most common type of event identified as the critical incident was being cut off (i.e., a driver changes lanes in front of you without ensuring a safe distance between his/her rear bumper and your front bumper) or nearly sideswiped by another vehicle (i.e., a driver adjacent to you attempts to move into your lane), both of which involve an unsafe lane change. A diverse array of other types of events were also reported, including a motorist running a red light or stop sign, tailgating, highbeaming, driving too slowly, or blocking the participant from merging or changing lanes.

\section{Exploratory factor analysis of aggressive and prosocial thoughts}

Given that the aggressive-thought and prosocial-thought scales were new, an exploratory factor analysis examined their dimensionality (see Table 7), using the same approach as in Study 1. As expected, all aggressive thought items loaded most strongly on the first factor. In terms of the prosocial thought items, two items loaded very strongly onto the second factor, whereas the third loaded onto both factors weakly. Given that the content of this item was the basis for the only prosocial behavior item remaining in this study (i.e., gesturing to the other driver that everything is okay) and that there were only two other items in the prosocial thought construct, this one item was retained for content validity. Without it, prosocial thought would have 
consisted exclusively of helping behavior. By retaining the item, a more thorough replication of the original questionnaire and model could be conducted in the second study. The factors were moderately correlated in the expected directions (interfactor correlation $=-.18$ ). Table 8 contains a bivariate correlations analysis and reliability estimates (along with means and standard deviations) of all variables included in Study 2.

\section{Path analysis}

The observed variables were not normally distributed. Mardia's measure of multivariate kurtosis was 3.31 for the thoughts model and 5.26 for the behaviors model, indicating moderate non-normality (Mardia, 1970). To find potential multivariate outliers, Mahalanobis distance was calculated twice, once for the set of variables to be included in the thoughts model and once for the set of variables to be included in the behaviors model. Four multivariate outliers were identified, three of which were common to both models. These four cases were deleted from the dataset, which led to an additional case being qualified as a multivariate outlier in the behaviors model. Deleting this case left a total of 194 participants for further analysis.

Given the moderate non-normality of the data, the path analysis for Study 2 again employed the Satorra-Bentler corrected model fit statistics and robust standard errors. As in Study 1 , the proposed models were estimated along with several direct paths that were expected to be mediated by one other variable in the model. Nonsignificant paths not part of Weiner's $(1995,1996,2001,2006)$ model were deleted in a step-by-step fashion.

In the initial thoughts model, with all direct paths included, the chi-square test, $\chi^{2}(8)=$ $10.04, p=.26$, indicated that the model had a good fit to the data. Other fit indices corroborated this finding $(\mathrm{CFI}=.99, \mathrm{RMSEA}=.04, \mathrm{SRMR}=.03)$. In the final thoughts model, with nonsignificant direct paths removed, most of the fit indices improved slightly, $\chi^{2}(14)=13.89, p=$ 
$.46, \mathrm{CFI}=1.00, \mathrm{RMSEA}=.00, \mathrm{SRMR}=.04$. The step-by-step removal of nonsignificant paths led to the deletion of six direct paths from the model; however, responsibility did not fully mediate the relationships between the causal dimensions of controllability and intentionality and the sympathy outcome. In addition, the hypothesized residual correlation between aggressive and prosocial thought was not significant. As this relationship was part of the hypothesized model, it was retained in the final model presented in Figure 4, which includes standardized path estimates. In light of the fact that responsibility did not mediate fully the relationship between the causal dimensions of controllability and intentionality and the sympathy outcome, partial mediation was again tested using the product of $z$-score approach. Results indicated that responsibility partially mediated these relationships $(p<.05)$. Overall, squared multiple correlations indicated that the model accounted for $39 \%$ of the variance in responsibility, $27 \%$ of the variance in anger, $27 \%$ of the variance in sympathy, $36 \%$ of the variance in aggressive thought, and $8 \%$ of the variance in prosocial thought.

In the initial behaviors model, with all direct paths included, the chi-square test was significant, $\chi^{2}(8)=29.03, p<.01$, and most of the other fit indices suggested an inadequate fit $(\mathrm{CFI}=.93, \mathrm{RMSEA}=.12, \mathrm{SRMR}=.05)$. With the non-significant direct paths removed, the fit indices improved slightly, $\chi^{2}(14)=34.77, p<.01, \mathrm{CFI}=.93, \mathrm{RMSEA}=.09, \mathrm{SRMR}=.06 . \mathrm{In}$ total, six direct paths were deleted from the model. As with the thoughts model, responsibility did not mediate fully the relationships between the causal dimensions of controllability and intentionality and the sympathy outcome. Subsequent tests for partial mediation were significant $(p<.05)$. The hypothesized residual correlation between aggressive and prosocial behavior was significant but positive. Finally, the path from sympathy to prosocial behavior was not significant, but because it was hypothesized as part of the original model, this path was retained 
in the final model (see Figure 5 for standardized path estimates). Squared multiple correlations indicated that the model accounted for $9 \%$ of the variance in aggressive behavior and less than $1 \%$ of the variance in prosocial behavior. Potential gender differences in the primary variables of interest were assessed, but none were found.

\section{Discussion}

Overall, the results strongly support a successful replication of the laboratory-based findings of Study 1 with the diary methodology of Study 2. A review of the diary entries revealed that a majority of drivers encountered at least one negative event involving another motorist within a 48-hr period. Over the course of the study, approximately three out of every four participants in the sample experienced a negative driving event that caused them to rate their anger toward the other motorist as 5 or higher on a 7-point scale. Demand characteristics may have contributed to the high prevalence of anger-provoking encounters, as participants were recruited specifically for involvement in a study of negative driving events. Nonetheless, these findings are consistent with previous reports that estimate anger to be a frequent occurrence on roadways (Mesken, Hagenzieker, Rothengatter, \& de Waard, 2007; Neighbors et al., 2002). The content of participants' most negative and upsetting driving events from the previous week were quite varied and included behaviors such as cutting off and sideswiping other motorists, tailgating, excessively slow driving, running red traffic lights or stop signs, and blocking merges or lane changes. The most frequently reported negative driving event was being cut off or nearly sideswiped by another vehicle, which is consistent with previous research (Britt \& Garrity, 2006; Wickens et al., 2005, 2011).

A modified model was developed for Study 2, due to the difficulty of interpolating the questionnaire from Study 1 to a questionnaire tapping the more personal meaning of driving 
events. This new model (i.e., the thoughts model) removed behavioral responses from Weiner's $(1995,1996,2001,2006)$ theory and replaced them with behavioral thoughts (i.e., behavioral options that the driver considered while driving). These thoughts were designed to closely parallel the behavioral items tested in Study 1, which asked what behaviors participants anticipated performing were they to find themselves in the hypothetical scenario. Drivers' angry thoughts about retaliating verbally or physically against an offending driver are strongly correlated with driving-related aggression (Deffenbacher, Petrilli, Lynch, Oetting, \& Swaim, 2003; Deffenbacher, White, \& Lynch, 2004).

The modified thoughts model fit the data well. As predicted, the three causal dimensions were all positively correlated, although the strength of these correlations was weaker than in Study 1. As predicted, all three causal dimensions were significantly related to responsibility. Interestingly, the strength of the relationship between intentionality and responsibility in Study 2 $\left(b^{*}=.19\right)$ was very similar to the parallel finding in Study $1\left(b^{*}=.14\right)$, suggesting that the NC-I manipulation failure may not have affected the strength of the relationship in Study 1. It is possible that for some participants, a lack of intention was perceived as negligence or as a lack of foresight on the part of the offending driver, and that this lack of intention was associated with a judgment of the offending driver as responsible for the negative event.

As predicted, responsibility was positively associated with anger and negatively associated with sympathy. Although findings for sympathy are at variance with the nonsignificant finding from Study 1 , these data are in keeping with meta-analytic findings linking low perceived responsibility with greater feelings of sympathy (Rudolph, Roesch, Greitemeyer, \& Weiner, 2004). Collectively, these data suggest that it is best to predict the attributional antecedents of sympathy in a more experimentally representative context, but more 
importantly, the data provide support for Weiner's (2006) extended attributional model of social motivation and moral emotions.

Also as predicted, responsibility fully mediated the relationship between all three causal dimensions and anger. Responsibility also fully mediated the relationship between locus of causality and sympathy. The relationships between the two remaining causal dimensions (controllability and intentionality) and sympathy were only partially mediated. As expected, aggressive thought was positively predicted by anger, and prosocial thought was positively predicted by sympathy. As expected, the residuals of anger and sympathy were negatively correlated. Contrary to predictions, but similar to the results of Study 1, there was no residual correlation between aggressive and prosocial thought. The correlations among variables in Study 2 were smaller than in Study 1, and the variance in each of the endogeneous variables accounted for by the model was less, which is not surprising given the more varied nature of driving events addressed and the lack of experimental control characterizing Study 2 . The greatest declines in variance accounted for in Study 1 versus Study 2 were responsibility (Study $1 R^{2}=.69$, Study 2 $R^{2}=.39$ ) and prosocial thought (Study $1 R^{2}=.28$, Study $2 R^{2}=.08$ ).

The parameter estimates of the behaviors model were essentially the same as those of the thoughts model, although differences could be seen with the behavioral constructs. Aggressive behavior seemed to fit well within the behaviors model, but this was not so for the prosocial behavior construct. Specifically, the relationship between sympathy and prosocial behavior was not significant, and the correlation between aggressive and prosocial behavior was significant, but in a positive direction. This suggests that the measure of prosocial behavior may have been inadequate. The items used to measure prosocial behavior in Study 1 were very limited, and were often based on hypothetical events (e.g., offering personal assistance to the driver), making 
revision of these items impossible for Study 2. Attributional theory may still prove useful in promoting prosocial driver behaviors, but the current research focus on negative events likely hampered the investigation of positive behavior.

Another noteworthy difference between the thoughts and behaviors models is the strength of the relationship between anger and aggressive thought versus behavior. In the case of thought, the standardized regression coefficient was .60 and in the case of behavior, it was .30. In addition, the amount of variance accounted for by the model was greater for aggressive thought $\left(R^{2}=.36\right)$ than for aggressive behavior $\left(R^{2}=.09\right)$. Clearly, the thoughts model more closely replicated the conditions of Study 1, in which the standardized regression coefficient between anger and aggressive behavior was .63 and the model accounted for $40 \%$ of the variance in aggressive behavior. It is possible that the lower regression coefficient in the thoughts model compared with the behaviors model in Study 2 reflects the fact that drivers do not enact all of the behaviors they consider. The mean scores for aggressive thought (4.46) and aggressive behavior (2.64) support this interpretation. Fortunately, given the low frequency of driver anger expressed on roadways, drivers usually inhibit their aggressive thoughts.

Given the strong correlations between thoughts and behaviors, future research may consider revising the model to include paths from thoughts to behaviors. Such a model would be a hybrid of Weiner's $(1995,1996,2001,2006)$ model and the theory of planned behavior (TPB; Ajzen, 1985), which addresses the link between behavioral intentions and actions. Given the weakness of the prosocial behavior construct in the current study, such a model was not tested here. 
General Discussion: Future Research and Applications

Overall, the findings of the current research support Weiner's $(1995,1996,2001,2006)$ attributional model of responsibility for social transgressions in a context that has not been used thus far to test this model. The causal dimensions provide a good means of classifying various types of offensive driver behavior, and the model, as a whole, provides a reliable means of predicting driver anger and aggression. With the exception of the behaviors model in Study 2, these studies also suggest that the model may provide a means of accounting for sympathy and prosocial behavior in the driving environment, although these constructs will need further attention before they can be fully understood. Differences between the thoughts and behaviors models in Study 2 were informative. The stronger relationship between anger and aggressive thought versus behavior, and the greater amount of variance within aggressive thought versus behavior that was accounted for by the model, could be interpreted as reflecting the fact that individuals do not enact all behavioral responses in their repertoire. Studies examining the relationship between intentions and behaviors across a diversity of contexts (e.g., condom use, healthy eating and exercise habits, smoking cessation, students' study habits, participation in collective action) have demonstrated a similar finding (Armitage \& Conner, 2001). Overall, the results of these two studies provide the necessary foundation for continued application of Weiner's model to the driving context and provide a framework to guide that research.

\section{Future Research to Address the Limitations of the Current Study}

\section{Expanding the methodological repertoire}

Expanding the methodology used to study driver attributions is essential to the advancement of this research. The written scenarios of Study 1 may have differed in ways beyond the intended levels of perceived controllability and intentionality. Moreover, the 
questionnaire methodology used in both studies may have inflated anger ratings through rumination (Rusting \& Nolen-Hoeksema, 1998), threatening the studies' external validity. Simulator technology offers great potential in studying the attribution process in vivo, and would permit testing using physiological, as well as behavioral, measures of driver anger and aggression. The importance of studying driver anger and aggression using multiple techniques is particularly important in light of recent findings that the empirically demonstrated relationship between driver anger and aggression is subject to common method variance (Nesbit et al., 2007). It might also be possible to utilize implicit measures of attributional tendencies or attitudes to overcome the limitations of self-report data. The Implicit Association Test (IAT) has just begun to be used in driving-related research (e.g., Hatfield, Fernandes, Faunce, \& Job, 2008; Sibley \& Harré, 2009a, 2009b) and may be able to inform the study of attributional processing in the driving context.

\section{Applying the model to drivers in other jurisdictions and to drivers with more experience}

It will also be important to ensure that Weiner's $(1995,1996,2001,2006)$ model applies to all driver behavior and not just to the behavior of young Canadian drivers comprising the majority of the present sample. Cross-cultural research has found both similarities and differences in self-reported aggressive driving behavior. Across cities or countries, drivers may attribute offensive behavior differently (Özkan, Lajunen, Parker, Sümer, \& Summala, 2010). In a similar vein, novice motorists are typically overconfident about their driving skills (Mynttinen et al., 2009). Many young drivers believe that they engage in less risky driving than their peers (Harré, Brandt, \& Houkamau, 2004) and are less likely than their peers to be involved in a collision (Glendon, Dorn, Davies, Matthews, \& Taylor, 1996; Matthews \& Moran, 1986). Although optimism biases are prevalent among all age groups, some studies have suggested that 
this bias is particularly pronounced among young people in the driving context (Harré et al., 2004; Matthews \& Moran, 1986). Overly positive misperceptions about one's own driving skills and abilities may serve to reduce one's tolerance for the objectionable behavior of other road users (Jiang, Li, \& Liu, 2008). Risky and aggressive driving is far less prevalent among older, more experienced motorists (Lajunen \& Parker, 2001; Smart, Mann, \& Stoduto, 2003).

\section{Future Research of Other Relevant Factors and Models}

Future research will also need to consider other factors and variables that might impact the cognitive-emotional-behavioral sequence identified in Weiner's (1995) model. Stereotypes, for example, have already been found to impact the responsibility judgments for drivers involved in a motor vehicle collision (Davies \& Patel, 2005). It might be worthwhile to determine how stereotypes about any number of driver characteristics might impact attributions for nearcollisions or other negative driving encounters. Does age, gender, or ethnicity affect drivingrelated attributions? Horn-honking latency in response to a vehicle stopped at a green traffic light has been found to differ based on the perceived degree of the offending driver's experience (via the presence versus absence of a learner's permit sticker; Yazawa, 2004), suggesting that perceptions of the offending driver's experience may impact responsibility judgments, anger, and aggression.

Future research may also assess how individual difference or personality variables influence Weiner's (1995, 1996, 2001, 2006) model. Weiner (1995) has suggested that those high in trait aggression are likely to possess a hostile attribution bias that influences their inferences about the responsibility of perceived offenders. Are there other individual difference variables impacting the cognitive-emotional-behavioral sequence outlined by Weiner? Research has already identified impulsivity (Wickens, Toplak, \& Wiesenthal, 2008), narcissism (Lustman, 
Wiesenthal, \& Flett, 2010), Type A behavior (Miles \& Johnson, 2003), trait anger (Deffenbacher et al., 2004; Lajunen \& Parker, 2001; Mesken et al., 2007; Nesbit et al., 2007), trait driver stress (Hennessy \& Wiesenthal, 2001), and the Big Five personality traits (i.e., extraversion, agreeableness, conscientiousness, neuroticism, openness; Miles \& Johnson, 2003; Sümer, Lajunen, \& Özkan, 2005) as predictors of driver anger and/or aggression.

It seems reasonable to assume that an extension of Weiner's (1995, 1996, 2001, 2006) model or a more integrative framework will need to be considered in order to account for the influence of personality and other relevant constructs. Alternative models of driver behavior (e.g., Ajzen's, 1985, theory of planned behavior, Matthews's, 2002, transactional model of driver stress and fatigue) have included environmental stressors, coping ability, and subjective norms in the development of driver aggression. Within the aggression context, the General Aggression Model (GAM; Anderson \& Bushman, 2002) is a highly comprehensive framework that may help to incorporate all of these constructs and models of driver behavior. Weiner's model and the GAM can be combined in a potentially meaningful manner. Within the GAM, continued research using Weiner's model would allow for a thorough understanding of the precise nature of causal attributions and judgments of responsibility as they relate to driver anger and aggression, and an understanding of why certain driving behaviors are perceived as more offensive than others.

\section{Attributional Theory as a Means to Improved Driver Safety}

Drivers need to be reminded that, like themselves, other motorists may also make unintended errors that are atypical of their usual driving behavior (Baxter, Macrae, Manstead, Stradling, \& Parker, 1990; Herzog, 1994). Drivers also need to be encouraged to make the effort to look for possible situational determinants of seemingly offensive driver behavior (Ellwanger, 
2007). Conversely, drivers need to consider that their own driving behaviors may be perceived as offensive, and may elicit anger and/or aggression from other road users (Baxter et al., 1990; Herzog, 1994). When recognizing that other motorists suffer from the same attributional biases as themselves, drivers may be more likely to acknowledge their own driving error and to communicate its unintended nature (e.g., with a wave), thereby reducing the likelihood that the victim motorist will respond with anger and/or aggression (Ellwanger, 2007). It may also be beneficial for young drivers to realize that they may overestimate their own driving skills and abilities.

Researchers have suggested initiating education campaigns and driver training programs designed to sensitize drivers to their misperceptions and attributional biases (Baxter et al., 1990; Ellwanger, 2007; Harré et al., 2004; Herzog, 1994; McKenna \& Albery, 2001). For instance, the public service campaign entitled 'Give 'em A Brake' encourages courtesy and patience for road construction workers (Ellwanger, 2007). It asks drivers to view construction delays as necessary and legitimate rather than the result of apathetic and unmotivated construction crews. By altering drivers' perceptions of, and attributions, for the delays, the campaign may be reducing the amount of stress experienced by motorists, and reducing the likelihood of aggressive behavior endangering motorists and construction crews. Similar campaigns could be developed to alter driver perceptions of, and attributions for, the negative driving behaviors and errors committed by other motorists. Likewise, driver attribution training programs could be developed and focused on making drivers aware of their cognitive biases in explaining their own and others' driver behaviors. Reminding motorists of their own driving errors has been shown to reduce anger in response to an offensive driving event (Takaku, 2006). Training programs could also focus on teaching drivers about how to communicate their intentions both before (e.g., using lane 
change and turn signals) and after (e.g., waving to indicate an apology or a sign of gratitude) a driving maneuver in order to reduce the chances of a miscommunication escalating into an aggressive episode. This may be particularly worthwhile given Renge's (2000) finding that novice drivers encounter more difficulty than experienced drivers in comprehending informal signals sometimes used in the driving environment (e.g., flashing headlights as a signal of thanks). Finally, the positive association between anger and aggression demonstrated in this research suggests that anger management training may prove beneficial for those drivers who allow their anger to escalate to aggressive behavior. 


\section{References}

Ajzen, I. (1985). From intentions to actions: A theory of planned behavior. In J. Kuhl \& J. Beckmann (Eds.), Action control: From cognition to behavior (pp. 11-39). Berlin: Springer-Verlag.

Anderson, C. A. (1983). The causal structure of situations: The generation of plausible causal attributions as a function of type of event situation. Journal of Experimental Social Psychology, 19, 185-203. doi:10.1016/0022-1031(83)90037-9

Anderson, C. A., \& Bushman, B. J. (2002). Human aggression. Annual Review of Psychology, 53, 27-51. doi:10.1146/annurev.psych.53.100901.135231

Arkkelin, D., Oakley, T., \& Mynatt, C. (1979). Effects of controllable versus uncontrollable factors on responsibility attributions: A single-subject approach. Journal of Personality and Social Psychology, 37, 110-115. doi:10.1037/0022-3514.37.1.110

Armitage, C. J., \& Conner, M. (2001). Efficacy of the Theory of Planned Behaviour: A metaanalytic review. British Journal of Social Psychology, 40, 471-499. doi:10.1348/014466601164939

Arnett, J. J., Offer, D., \& Fine, M. A. (1997). Reckless driving in adolescence: 'State' and 'trait' factors. Accident Analysis and Prevention, 29, 57-63. doi:10.1016/S00014575(97)87007-8

Baxter, J. S., Macrae, C. N., Manstead, A. S. R., Stradling, S. G., \& Parker, D. (1990). Attributional biases and driver behavior. Social Behavior, 5, 185-192.

Britt, T. W., \& Garrity, M. J. (2006). Attributions and personality as predictors of the road rage response. British Journal of Social Psychology, 45, 127-147. doi:10.1348/014466605X41355 
Davies, G. M., \& Patel, D. (2005). The influence of car and driver stereotypes on attributions of vehicle speed, position on the road and culpability in a road accident scenario. Legal and Criminological Psychology, 10, 45-62. doi:10.1348/135532504X15394

Deffenbacher, J. L., Petrilli, R. T., Lynch, R. S., Oetting, E. R., \& Swaim, R. C. (2003). The Driver's Angry Thoughts Questionnaire: A measure of angry cognitions when driving. Cognitive Therapy and Research, 27, 383-402. doi:10.1023/A:1025403712897

Deffenbacher, J. L., White, G. S., \& Lynch, R. S. (2004). Evaluation of two new scales assessing driving anger: The Driving Anger Expression Inventory and the Driver's Angry Thoughts Questionnaire. Journal of Psychopathology and Behavioral Assessment, 26, 87-99. doi:10.1023/B:JOBA.0000013656.68429.69

Ellwanger, S. J. (2007). Strain, attribution, and traffic delinquency among young drivers: Measuring and testing general strain theory in the context of driving. Crime \& Delinquency, 53, 523-551. doi:10.1177/0011128706295991

Feather, N. T. (1996). Reactions to penalties for an offense in relation to authoritarianism, values, perceived responsibility, perceived seriousness, and deservingness. Journal of Personality and Social Psychology, 71, 571-587. doi:10.1037/0022-3514.71.3.571

Feather, N. T. (1999). Values, achievement, and justice: Studies in the psychology of deservingness. New York, NY: Kluwer Academic/Plenum Publishers.

Feather, N. T., \& Deverson, N. H. (2000). Reactions to a motor-vehicle accident in relation to mitigating circumstances and the gender and moral worth of the driver. Journal of Applied Social Psychology, 30, 77-95. doi:10.1111/j.1559-1816.2000.tb02306.x 
Fincham, F. D., \& Bradbury, T. N. (1992). Assessing attributions in marriage: The Relationship Attribution Measure. Journal of Personality and Social Psychology, 62, 457-468. doi:10.1037/0022-3514.62.3.457

Fincham, F. D., \& Jaspars, J. M. (1980). Attribution of responsibility: From man the scientist to man as lawyer. In L. Berkowitz (Ed.), Advances in experimental social psychology (Vol. 13, pp. 81-138). New York, NY: Academic. doi:10.1016/S0065-2601(08)60131-8

Fincham, F. D., \& Roberts, C. (1985). Intervening causation and the mitigation of responsibility for harm doing: The role of limited mental capacities. Journal of Experimental Social Psychology, 21, 178-194. doi:10.1016/0022-1031(85)90014-9

Glendon, A. I., Dorn, L., Davies, D. R., Matthews, G., \& Taylor, R. G. (1996). Age and gender differences in perceived accident likelihood and driver competences. Risk Analysis, 16, 755-762. doi:10.1111/j.1539-6924.1996.tb00826.x

Greitemeyer, T., Rudolph, U., \& Weiner, B. (2003). Whom would you rather help: An acquaintance not responsible for her plight or a responsible sibling? The Journal of Social Psychology, 143, 331-340. doi:10.1080/00224540309598448

Harré, N., Brandt, T., \& Houkamau, C. (2004). An examination of the actor-observer effect in young drivers' attributions for their own and their friends' risky driving. Journal of Applied Social Psychology, 34, 806-824. doi:10.1111/j.1559-1816.2004.tb02572.x

Hatfield, J., Fernandes, R., Faunce, G., \& Job, R. F. S. (2008). An implicit non-self-report measure of attitudes to speeding: Development and validation. Accident Analysis and Prevention, 40, 616-627. doi:10.1016/j.aap.2007.08.020

Heider, F. (1944). Social perception and phenomenal causality. Psychological Review, 51, 358374. doi:10.1037/h0055425 
Heider, F. (1958). The psychology of interpersonal relations. New York: John Wiley \& Sons, Inc.

Hennessy, D. A., \& Wiesenthal, D. L. (1999). Traffic congestion, driver stress, and driver aggression. Aggressive Behavior, 25, 409-423. doi:10.1002/(SICI)10982337(1999)25:6<409::AID-AB2>3.0.CO;2-0

Hennessy, D. A., \& Wiesenthal, D. L. (2001). Gender, driver aggression, and driver violence: An applied evaluation. Sex Roles, 44, 661-676. doi:10.1023/A:1012246213617

Hennessy, D. A., \& Wiesenthal, D. L. (2002). The relationship between driver aggression, violence, and vengeance. Violence and Victims, 17, 707-718.

Herzog, T. A. (1994). Automobile driving as seen by the actor, the active observer, and the passive observer. Journal of Applied Social Psychology, 24, 2057-2074. doi:10.1111/j.1559-1816.1994.tb00574.x

Islam, M. R., \& Hewstone, M. (1993). Intergroup attributions and affective consequences in majority and minority groups. Journal of Personality and Social Psychology, 64, 936950. doi:10.1037/0022-3514.64.6.936

Jiang, L., Li, Y., \& Liu, X. (2008). The effects of motor impulsiveness and optimism bias on risky driving behavior in Chinese urban areas. Proceedings of the 11th International IEEE Conference on Intelligent Transportation Systems, Beijing, China (pp. 605-609). Downloaded from http://www.asmemesa.org/itsc08/ITSC2008/papers/0113.pdf January 4, 2011.

Jones, E. E., \& Davis, K. E. (1966). From acts to dispositions: The attribution process in person perception. In L. Berkowitz (Ed.), Advances in experimental social psychology (Vol. 2, pp. 219-266). New York, NY: Academic. doi:10.1016/S0065-2601(08)60107-0 
Kelley, H. H. (1967). Attribution theory in social psychology. In D. Levine (Ed.), Nebraska Symposium on Motivation (Vol. 15, pp. 192-240). Lincoln, NE: University of Nebraska Press.

Kline, R. B. (2005). Principles and practice of structural equation modeling. New York: The Guilford Press.

Knapper, C. K., \& Cropley, A. J. (1978). 'Towards a social psychology of the traffic environment'. In D. F. Burkhardt \& W. H. Ittelson (Eds.), Environmental assessment of socioeconomic systems (pp. 263-278). New York: Plenum.

Knapper, C. K., \& Cropley, A. J. (1981). Social and interpersonal factors in driving. In G. M. Stephenson \& J. M. Davis (Eds.), Progress in applied social psychology (Vol. 1, pp. 191220). Chichester, England: John Wiley \& Sons, Ltd.

Lajunen, T., \& Parker, D. (2001). Are aggressive people aggressive drivers? A study of the relationship between self-reported general aggressiveness, driver anger and aggressive driving. Accident Analysis and Prevention, 33, 243-255. doi:10.1016/S00014575(00)00039-7

Lawton, R., Parker, D., Stradling S. G., \& Manstead, A. S. R. (1997). Predicting road traffic accidents: The role of social deviance and violations. British Journal of Psychology, 88, 249-262. doi:10.1111/j.2044-8295.1997.tb02633.x

Lustman, M., Wiesenthal, D. L., \& Flett, G. L. (2010). Narcissism and aggressive driving: Is inflated self-esteem a road hazard? Journal of Applied Social Psychology, 40, 1423-1449. doi:10.1111/j.1559-1816.2010.00624.x 
MacCallum, R. C., Browne, M. W., \& Sugawara, H. M. (1996). Power analysis and determination of sample size for covariance structure modeling. Psychological Methods, 1, 130-149. doi:10.1037/1082-989X.1.2.130

MacKinnon, D. P., Fritz, M. S., Williams, J., \& Lockwood, C. M. (2007). Distribution of the product confidence limits for the indirect effect: Program PRODCLIN. Behavior Research Methods, 39, 384-389. doi:10.3758/BF03193007

Mardia, K.V. (1970). Measures of multivariate skewness and kurtosis with applications. Biometrika, 57, 519-530. doi:10.1093/biomet/57.3.519

Marjanovic, Z., Greenglass, E. R., Struthers, C. W., \& Faye, C. (2009). Helping following natural disasters: A social-motivational analysis. Journal of Applied Social Psychology, 39, 2604-2625. doi:10.1111/j.1559-1816.2009.00540.x

Martinez, R. (1997). The statement of the Honourable Ricardo Martinez, M.D., Administrator, National Highway Traffic Safety Administration before the Subcommittee on Surface Transportation, Committee on Transportation and Infrastructure, U.S. House of Representatives, July 17, 1997.

Matthews, G. (2002). Towards a transactional ergonomics for driver stress and fatigue. Theoretical Issues in Ergonomics Science, 3, 195-211. doi:10.1080/14639220210124120

Matthews, M. L., \& Moran, A. R. (1986). Age differences in male drivers' perception of accident risk: The role of perceived driving ability. Accident Analysis and Prevention, 18, 299-313. doi:10.1016/0001-4575(86)90044-8

McKenna, F. P., \& Albery, I. P. (2001). Does unrealistic optimism change following a negative experience? Journal of Applied Social Psychology, 31, 1146-1157. doi: 10.1111/j.15591816.2001.tb02667.x 
McKillip, J., \& Posavac, E. J. (1975). Judgments of responsibility for an accident. Journal of Personality, 43, 248-265. doi:10.1111/j.1467-6494.1975.tb00705.x

Mesken, J., Hagenzieker, M. P., Rothengatter, T., \& de Waard, D. (2007). Frequency, determinants, and consequences of different drivers' emotions: An on-the-road study using self-reports, (observed) behavior, and physiology. Transportation Research Part F, 10, 458-475. doi:10.1016/j.trf.2007.05.001

Miles, D. E., \& Johnson, G. L. (2003). Aggressive driving behaviors: are there psychological and attitudinal predictors?. Transportation Research Part F, 6, 147-161. doi:10.1016/S13698478(03)00022-6

Mynttinen, S., Sundström, A., Koivukoski, M., Hakuli, K., Keskinen, E., \& Henriksson, W. (2009). Are novice drivers overconfident? A comparison of self-assessed and examinerassessed driver competences in a Finnish and Swedish sample. Transportation Research Part F, 12, 120-130. doi:10.1016/j.trf.2008.09.002

Neighbors, C., Vietor, N. A., \& Knee, C. R. (2002). A motivational model of driving anger and aggression. Personality and Social Psychology Bulletin, 28, 324-335. doi:

$10.1177 / 0146167202286004$

Nesbit, S. M., Conger, J. C., \& Conger, A. J. (2007). A quantitative review of the relationship between anger and aggressive driving. Aggression and Violent Behavior, 12, 156-176. doi:10.1016/j.avb.2006.09.003

Nunnally, J. C., \& Bernstein, I. H. (1994). Psychometric theory ( $3^{\text {rd }}$ ed.). Toronto: McGraw-Hill, Inc. 
Özkan, T., Lajunen, T., Parker, D., Sümer, N., \& Summala, H. (2010). Symmetric relationship between self and others in aggressive driving across gender and countries. Traffic Injury Prevention, 11, 228-239. doi:10.1080/15389581003788864

Parker, D., Lajunen, T., \& Summala, H. (2002). Anger and aggression among drivers in three European countries. Accident Analysis and Prevention, 34, 229-235. doi:10.1016/S00014575(01)00018-5

Renge, K. (2000). Effect of driving experience on drivers' decoding process of roadway interpersonal communication. Ergonomics, 43, 27-39. doi:10.1080/001401300184648

Rudolph, V., Roesch, S. C., Greitemeyer, T., \& Weiner, B. (2004). A meta-analytic review of help giving and aggression from an attributional perspective: Contributions to a general theory of motivation. Cognition and Emotion, 18, 815-848.

doi:10.1080/02699930341000248

Rusting, C. L., \& Nolen-Hoeksema, S. (1998). Regulating responses to anger: Effects of rumination and distraction on angry mood. Journal of Personality and Social Psychology, 74, 790-803. doi:10.1037/0022-3514.74.3.790

Satorra, A., \& Bentler, P. M. (1994). Corrections to test statistics and standard errors in covariance structure analysis. In A. von Eye \& C. C. Clogg (Eds.), Latent variables analysis: Applications for developmental research (pp. 399-419). Thousand Oaks, CA: Sage Publications, Inc.

Satorra, A., \& Bentler, P. M. (2001). A scaled difference chi-square test statistic for moment structure analysis. Psychometrika, 66, 507-514. doi:10.1007/BF02296192

Shaver, K. G. (1985). The attribution of blame: Causality, responsibility, and blameworthiness. New York: Springer-Verlag. 
Shultz, T. R., \& Darley, J. M. (1991). An information-processing model of retributive moral judgments based on “legal reasoning”. In W. M. Kurtines \& J. L. Gewirtz (Eds.), Handbook of moral behavior and development - Volume 2: Research (pp. 247-278). Hillsdale, NJ: Lawrence Erlbaum Associates, Publishers.

Sibley, C. G., \& Harré, N. (2009a). The impact of different styles of traffic safety advertisement on young drivers' explicit and implicit self-enhancement biases. Transportation Research Part F, 12, 159-167. doi:10.1016/j.trf.2008.11.001

Sibley, C. G., \& Harré, N. (2009b). A gender role socialization model of explicit and implicit biases in driving self-enhancement. Transportation Research Part F, 12, 452-461. doi:10.1016/j.trf.2009.08.006

Smart, R. G., Mann, R. E., \& Stoduto, G. (2003). The prevalence of road rage: Estimates from Ontario. Canadian Journal of Public Health, 94, 247-250.

Snyder, D. F. (1997). Statement of David F. Snyder, Assistant General Counsel, American Insurance Association, representing advocates for highway and auto safety before the Subcommittee on Surface Transportation, Committee on Transportation and Infrastructure, U.S. House of Representatives, July 17, 1997.

Struthers, C. W., Dupuis, R., \& Eaton, J. (2005). Promoting forgiveness among co-workers following a workplace transgression: The effects of social motivation training. Canadian Journal of Behavioural Science, 37, 299-308. doi:10.1037/h0087264

Struthers, C. W., Eaton, J., Mendoza, R., Santelli, A., G., \& Shirvani, N. (2010). The interrelationship among injured parties' attributions of responsibility, appraisal of the appropriateness to forgive the transgressor, forgiveness, and repentance. Journal of Applied Social Psychology, 40, 970-1002. doi:10.1111/j.1559-1816.2010.00607.x 
Sümer, N., Lajunen, T., \& Özkan, T. (2005). Big five personality traits as the distal predictors of road accident involvement. In G. Underwood (Ed.). Traffic and transport psychology: Theory and application - Proceedings of the ICTTP 2004 (pp. 215-227). New York: Elsevier.

Takaku, S. (2006). Reducing road rage: An application of the dissonance-attribution model of interpersonal forgiveness. Journal of Applied Social Psychology, 36, 2362-2378. doi:10.1111/j.0021-9029.2006.00107.x

Tversky, A. \& Kahneman, D. (1974). Judgment under uncertainty: Heuristics and biases. Science, 185, 1124-1131. doi:10.1126/science.185.4157.1124

Vallières, E. F., Bergeron, J., \& Vallerand, R. J. (2005). The role of attributions and anger in aggressive driving behaviors. In G. Underwood (Ed.). Traffic and transport psychology: Theory and application - Proceedings of the ICTTP 2004 (pp. 181-190). New York: Elsevier.

Weiner, B. (1979). A theory of motivation for some classroom experiences. Journal of Educational Psychology, 71, 3-25. doi:10.1037/0022-0663.71.1.3

Weiner, B. (1985). An attributional theory of achievement motivation and emotion. Psychological Review, 92, 548-573. doi:10.1037/0033-295X.92.4.548

Weiner, B. (1995). Judgments of responsibility: A foundation for a theory of social conduct. New York: The Guilford Press.

Weiner, B. (1996). Searching for order in social motivation. Psychological Inquiry, 7, 199-216. doi:10.1207/s15327965pli0703_1 
Weiner, B. (2001). Responsibility for social transgressions: An attributional analysis. In B. F. Malle, L. J. Moses, \& D. A. Baldwin (Eds.), Intentions and intentionality (pp. 331-344). Cambridge, MA: MIT Press.

Weiner, B. (2006). Social motivation, justice, and the moral emotions: An attributional approach. Mahwah, NJ: Erlbaum.

Weiner, B., Perry, R. P., \& Magnusson, J. (1988). An attributional analysis to reactions of stigmas. Journal of Personality and Social Psychology, 55, 738-748. doi:10.1037/00223514.55.5.738

Weiner, B., Russell, D., \& Lerman, D. (1978). Affective consequences of causal ascriptions. In J. H. Harvey, W. J. Ickes, \& R. F. Kidd (Eds.), New directions in attribution research (Vol. 2, pp. 59-88). Hillsdale, NJ: Erlbaum.

Wells-Parker, E., Ceminsky, J., Hallberg, V., Snow, R. W., Dunaway, G., Suiling, S., et al. (2002). An exploratory study of the relationship between road rage and crash experience in a representative sample of US drivers. Accident Analysis and Prevention, 34, 271-278. doi:10.1016/S0001-4575(01)00021-5

Wickens, C. M., Toplak, M. E., \& Wiesenthal, D. L. (2008). Cognitive failures as predictors of driving errors, lapses, and violations. Accident Analysis and Prevention, 40, 1223-1233. doi:10.1016/j.aap.2008.01.006

Wickens, C. M., Wiesenthal, D. L., Hall, A., \& Roseborough, J. (2011). Driver anger on the information superhighway: A final report. Proceedings of the $21^{\text {st }}$ Canadian Multidisciplinary Road Safety Conference, Halifax, Nova Scotia. Retrieved from http://www.carsp.ca/documents/139 
Wickens, C. M., Wiesenthal, D. L., \& Rippey, K. (2005). Motorists’ perceptions of aggressive driving: A comparative analysis of Ontario and California drivers. In D. A. Hennessy \& D. L. Wiesenthal (Eds.), Contemporary issues in road user behavior and traffic safety (pp. 23-36). Hauppauge, NY: Nova Science Publishers.

Yazawa, H. (2004). Effects of inferred social status and a beginning driver's sticker upon aggression of drivers in Japan. Psychological Reports, 94, 1215-1220. doi:10.2466/pr0.94.3c.1215-1220 
Table 1

Study 1: Factor Structure and Pattern Coefficients of Controllability and Intentionality Items

Factor Structure $\quad$ Factor Pattern

Intended Factor and Item

Factor $1 \quad$ Factor $2 \quad$ Factor $1 \quad$ Factor 2

1. Controllability: Would you say that the main .79

.43

.77

.05

reason for the other driver cutting you off was: Not

Controllable by the Driver $(=7)$... Controllable by

the Driver (=1)

2. Controllability: Do you believe the cause of the

.88

.51

.83

.10

event (i.e., the cause of the other driver cutting you off) was beyond the driver's power?: Very much so $(=1)$... Not at all $(=7)$

3. Controllability: Do you think this driving event (i.e., the other driver cutting you off) was controllable?: Very much so $(=7) \ldots$ Not at all $(=1)$

4. Controllability: Do you think this driving event

.89 (i.e., the other driver cutting you off) was preventable?: Not at all $(=1) \ldots$ Very much so $(=7)$

5. Controllability: Do you believe that the other

.76 driver could have easily avoided cutting you off?: Very much so $(=7) \ldots$ Not at all $(=1)$

6. Intentionality: Do you believe that the other

.86

.01 .86 $(=7) \ldots$ Not at all $(=1)$

7. Intentionality: Do you think the other driver deliberately cut you off?: Not at all $(=1)$... Very much so $(=7)$

8. Intentionality: I think the other driver cut me off .54

.79

.20 .68 by accident: Very much so $(=1) \ldots$ Not at all $(=7)$

9. Intentionality: I think the other driver cut me off .41 .88 $-.04$ .90 on purpose: Very much so $(=7) \ldots$ Not at all $(=1)$ 
Note. The factor structure matrix contains the bivariate correlations of the items with the factors. The factor pattern matrix contains the regression coefficients, indicating the relative importance of the item to the factor with all other items separated out. 
Table 2

Study 1: Factor Pattern Coefficients of Responsibility Items

Intended Factor and Item $\quad$ Factor

1. Responsibility: Do you think the driver was to $\quad .81$ blame for cutting you off?: Not at all $(=1)$... Very much so $(=7)$

2. Responsibility: How responsible was the driver $\quad .64$ for cutting you off?: Extremely responsible $(=7) \ldots$ Not at all responsible $(=1)$

3. Responsibility: How accountable do you think the driver was for cutting you off?: Not at all accountable $(=1)$...Extremely accountable $(=7)$

4. Responsibility: Do you think the driver should answer for this event (i.e., for cutting you off)?: Very much so $(=7) \ldots$ Not at all $(=1)$ 
Table 3

Study 1: Factor Structure and Pattern Coefficients of Anger and Sympathy/Concern Items

Factor Structure $\quad$ Factor Pattern

Intended Factor and Item

\begin{tabular}{llll}
\hline Factor 1 & Factor 2 & Factor 1 & Factor 2
\end{tabular}

1. Anger: How angry do you feel toward this .88

$-.47$

.87

$-.02$

driver?: Extremely angry $(=7)$... Not at all angry $(=1)$

2. Anger: How upset do you feel toward this .86 $-.44$

.86 driver?: Extremely upset $(=7)$... Not at all upset $(=1)$

3. Anger: How mad do you feel toward this driver?: Not at all mad $(=1) \ldots$ Extremely mad $(=7)$

$-.46$

.88

4. Anger: How much does this driver frustrate .87

$-.42$

.88 you?: Not at all $(=1) \ldots$ Very much $(=7)$

5. Anger: How much does this driver aggravate you?: Not at all $(=1) \ldots$ Very much so $(=7)$

6. Sympathy/Concern: How much sympathy do

.82 you have for this driver?: No sympathy at all $(=1) \ldots$ A great deal of sympathy $(=7)$

7. Sympathy/Concern: How much compassion do $(=1) \ldots$ A great deal of compassion $(=7)$

8. Sympathy/Concern: How much empathy do you $-.42$ .89 .05 .92 have for this driver?: No empathy at all $(=1)$...A great deal of empathy $(=7)$

\section{Factor 1 Factor 2}

$55 \% \quad 42 \%$


Note. The factor structure matrix contains the bivariate correlations of the items with the factors. The factor pattern matrix contains the regression coefficients, indicating the relative importance of the item to the factor with all other items separated out. 
Table 4

Study 1: Factor Pattern Coefficients of Locus of Causality Items

Intended Factor and Item $\quad$ Factor

1. Locus of causality: Would you say that the main
cause of the other driver cutting you off: Reflected
an aspect of the driver $(=7)$...Reflected an aspect of
the situation $(=1)$

2. Locus of causality: Would you say that something about the situation made the motorist cut you off?: Very much so $(=1) \ldots$ Not at all $(=7)$

3. Locus of causality: Would you say that the main reason for the other driver cutting you off was because of: Something specific to the situation $(=1) \ldots$ Something specific to the driver $(=7)$

4. Locus of causality: Would you say that something about the motorist made him/her cut you off?: Very much so $(=7)$... Not at all $(=1)$

5. Locus of causality: Would you say that the main cause of the other driver cutting you off was due to an aspect of the situation/ environment?: Very much so $(=1) \ldots$ Not at all $(=7)$

6. Locus of causality: Would you say that the main cause of the other driver cutting you off was due to an aspect of the driver?: Very much so $(=7) \ldots$ Not at all $(=1)$ 
Table 5

Study 1: Factor Structure and Pattern Coefficients for Minor Aggressive and Prosocial Behavior Items

Intended Factor and Item

Factor Structure

Factor Pattern

you would use your horn and/or flash your lights?:

Not at all likely $(=1) \ldots$ Extremely likely $(=7)$

2. Minor aggressive behavior: How likely is it that

Factor $1 \quad$ Factor 2 Factor $1 \quad$ Factor 2
you would swear at and/or verbally abuse the other .82

.45

$-.01$

.09 driver?: Extremely likely $(=7)$... Not at all likely $(=1)$

3. Minor aggressive behavior: How likely is it that you would yell at the other driver?: Not at all likely $(=1) \ldots$ Extremely likely (=7)

4. Minor aggressive behavior: How likely is it that .87 $-.22$ you would gesture (e.g., wave your fist, "give him/her the finger") at the other driver?:

Extremely likely $(=7) \ldots$ Not at all likely $(=1)$

5. Minor aggressive behavior: How likely is it that you would tailgate/follow closely the other driver in order to teach him/her a lesson?: Not at all likely $(=1) \ldots$ Extremely likely $(=7)$

6. Prosocial behavior: How likely is it that you would gesture/signal to the other driver that everything is okay?: Not at all likely $(=1) \ldots$ Extremely likely $(=7)$

7. Prosocial behavior: If you saw this driver in need of assistance further down the road, how likely is it that you would call to get this driver help (e.g., tow truck, police)?: Extremely likely $(=7)$... Not at all likely $(=1)$

8. Prosocial behavior: How likely is it that you $-.15 \quad .86$ 
this driver if it were needed further down the road?: Not at all likely $(=1) .$. Extremely likely $(=7)$

\section{Factor 1 Factor 2}

Variance accounted for

$34 \% \quad 25 \%$

Note. The factor structure matrix contains the bivariate correlations of the items with the factors.

The factor pattern matrix contains the regression coefficients, indicating the relative importance of the item to the factor with all other items separated out. 
Table 6

Study 1: Bivariate Correlations and Reliability Analysis

\begin{tabular}{|c|c|c|c|c|c|c|c|c|}
\hline & 1. & 2. & 3. & 4. & 5. & 6. & 7. & 8. \\
\hline 1. Controllability & - & & & & & & & \\
\hline 2. Intentionality & .49 & - & & & & & & \\
\hline $\begin{array}{l}\text { 3. Locus of } \\
\text { causality }\end{array}$ & .74 & .65 & - & & & & & \\
\hline 4. Responsibility & .79 & .57 & .74 & - & & & & \\
\hline 5. Anger & .53 & .54 & .57 & .57 & - & & & \\
\hline 6. Sympathy & -.62 & -.50 & -.59 & -.57 & -.51 & - & & \\
\hline $\begin{array}{l}\text { 7. Aggressive } \\
\text { behavior }\end{array}$ & .36 & .44 & .48 & .43 & .63 & -.40 & - & \\
\hline $\begin{array}{l}\text { 8. Prosocial } \\
\text { behavior }\end{array}$ & -.45 & -.31 & -.40 & -.28 & -.28 & .53 & -.22 & - \\
\hline Number of items & 5 & 4 & 6 & 4 & 5 & 3 & 5 & 3 \\
\hline Coefficient $\alpha^{\mathrm{a}}$ & .92 & .92 & .89 & .75 & .94 & .91 & .83 & .70 \\
\hline Mean & 4.73 & 3.23 & 3.64 & 4.49 & 4.48 & 3.12 & 3.50 & 3.57 \\
\hline$S D$ & 1.42 & 1.52 & 1.32 & 1.27 & 1.40 & 1.33 & 1.39 & 1.45 \\
\hline
\end{tabular}

Note. All correlations are significant at $p \leq .01$.

${ }^{\mathrm{a}} N=214$. 
Table 7

Study 2: Factor Structure and Pattern Coefficients for Aggressive and Prosocial Thought Items

Factor Structure $\quad$ Factor Pattern

Intended Factor and Item

Factor $1 \quad$ Factor $2 \quad$ Factor $1 \quad$ Factor 2

1. Aggressive thought: To what extent did you .29

$-.07$

$.29-.02$

THINK ABOUT tailgating/following closely the other driver in order to teach him/her a lesson?:

Not at all $(=1) \ldots$ Very much so $(=7)$

2. Aggressive thought: To what extent did you

$-.19$

.56

THINK ABOUT swearing at and/or verbally abusing the other driver?: Very much so $(=7)$... Not at all $(=1)$

3. Aggressive thought: To what extent did you THINK ABOUT yelling at the other driver?: Not .85 $-.12$ .86 .04 at all $(=1) \ldots$ Very much so $(=7)$

4. Aggressive thought: To what extent did you THINK ABOUT gesturing (e.g., waving your fist, "giving him/her the finger") at the other driver?: Very much so $(=7) \ldots$ Not at all $(=1)$

5. Aggressive thought: To what extent did you THINK ABOUT using your horn and/or flashing your lights?: Not at all $(=1) \ldots$ Very much so $(=7)$

6. Prosocial thought: To what extent did you

.14 THINK ABOUT gesturing/signaling to the other driver that everything was okay?: Not at all $(=1) \ldots$ Very much so $(=7)$

7. Prosocial thought: If you had seen this driver in $-.19$ .91 $-.03$ .91 need of assistance further down the road, how likely is it that you would have called to get this driver help (e.g., tow truck, police)?: Extremely likely $(=7)$... Not at all likely $(=1)$

8. Prosocial thought: How likely is it that you $-.17$

.97

.01 .98 would have stopped your vehicle and offered assistance to this driver if it had been needed further down the road?: Not at all likely 
$(=1) \ldots$ Extremely likely $(=7)$

\section{Factor $1 \quad$ Factor 2}

Variance accounted for

$26 \% \quad 23 \%$

Note. The factor structure matrix contains the bivariate correlations of the items with the factors.

The factor pattern matrix contains the regression coefficients, indicating the relative importance of the item to the factor with all other items partialled out. 
Table 8

Study 2: Bivariate Correlations and Reliability Analysis

\begin{tabular}{|c|c|c|c|c|c|c|c|c|c|c|}
\hline & 1. & 2. & 3. & 4. & 5. & 6. & 7. & 8. & 9. & 10. \\
\hline 1. Controllability & - & & & & & & & & & \\
\hline 2. Intentionality & $.15^{*}$ & - & & & & & & & & \\
\hline $\begin{array}{l}\text { 3. Locus of } \\
\text { causality }\end{array}$ & $.38 * *$ & $.30 * *$ & - & & & & & & & \\
\hline 4. Responsibility & $.51 * *$ & $.33 * *$ & $.48 * *$ & - & & & & & & \\
\hline 5. Anger & $.27 * *$ & $.25 * *$ & $.25^{* *}$ & $.52 * *$ & - & & & & & \\
\hline 6. Sympathy & $-.41 * *$ & $-.34 * *$ & $-.33 * *$ & $-.42 * *$ & $-.44 * *$ & - & & & & \\
\hline $\begin{array}{l}\text { 7. Aggressive } \\
\text { thoughts }\end{array}$ & .14 & $.20 * *$ & .12 & $.30 * *$ & $.60 * *$ & $-.19 * *$ & - & & & \\
\hline $\begin{array}{l}\text { 8. Prosocial } \\
\text { thoughts }\end{array}$ & $-.20 * *$ & $-.20 * *$ & $-.16^{*}$ & -.14 & -.08 & $.27 * *$ & -.04 & - & & \\
\hline $\begin{array}{l}\text { 9. Aggressive } \\
\text { behavior }\end{array}$ & -.09 & .12 & .09 & .09 & $.31 * *$ & .03 & $.57 * *$ & .10 & - & \\
\hline $\begin{array}{l}\text { 10. Prosocial } \\
\text { behavior }\end{array}$ & $-.27 * *$ & .08 & -.13 & -.13 & .02 & .08 & .12 & $.32 * *$ & $.38 * *$ & - \\
\hline Number of items & 5 & 4 & 6 & 4 & 5 & 3 & 5 & 3 & 5 & 1 \\
\hline
\end{tabular}




\begin{tabular}{|c|c|c|c|c|c|c|c|c|c|c|}
\hline Coefficient $\alpha$ & .83 & .90 & .58 & .67 & .94 & .83 & .74 & .66 & .72 & - \\
\hline Mean $^{\mathrm{a}}$ & 6.30 & 4.95 & 4.98 & 5.80 & 5.53 & 1.93 & 4.41 & 3.25 & 2.61 & 1.66 \\
\hline$S D^{\mathrm{a}}$ & 0.98 & 1.73 & 1.00 & 1.15 & 1.29 & 1.03 & 1.56 & 1.61 & 1.48 & 1.49 \\
\hline
\end{tabular}




$\begin{array}{cccc}\text { CAUSAL } & \text { CAUSAL } & \text { EMOTIONAL } & \text { BEHAVIORAL } \\ \text { DIMENSIONS } & \text { JUDGMENT } & \text { RESPONSES } & \text { RESPONSES }\end{array}$

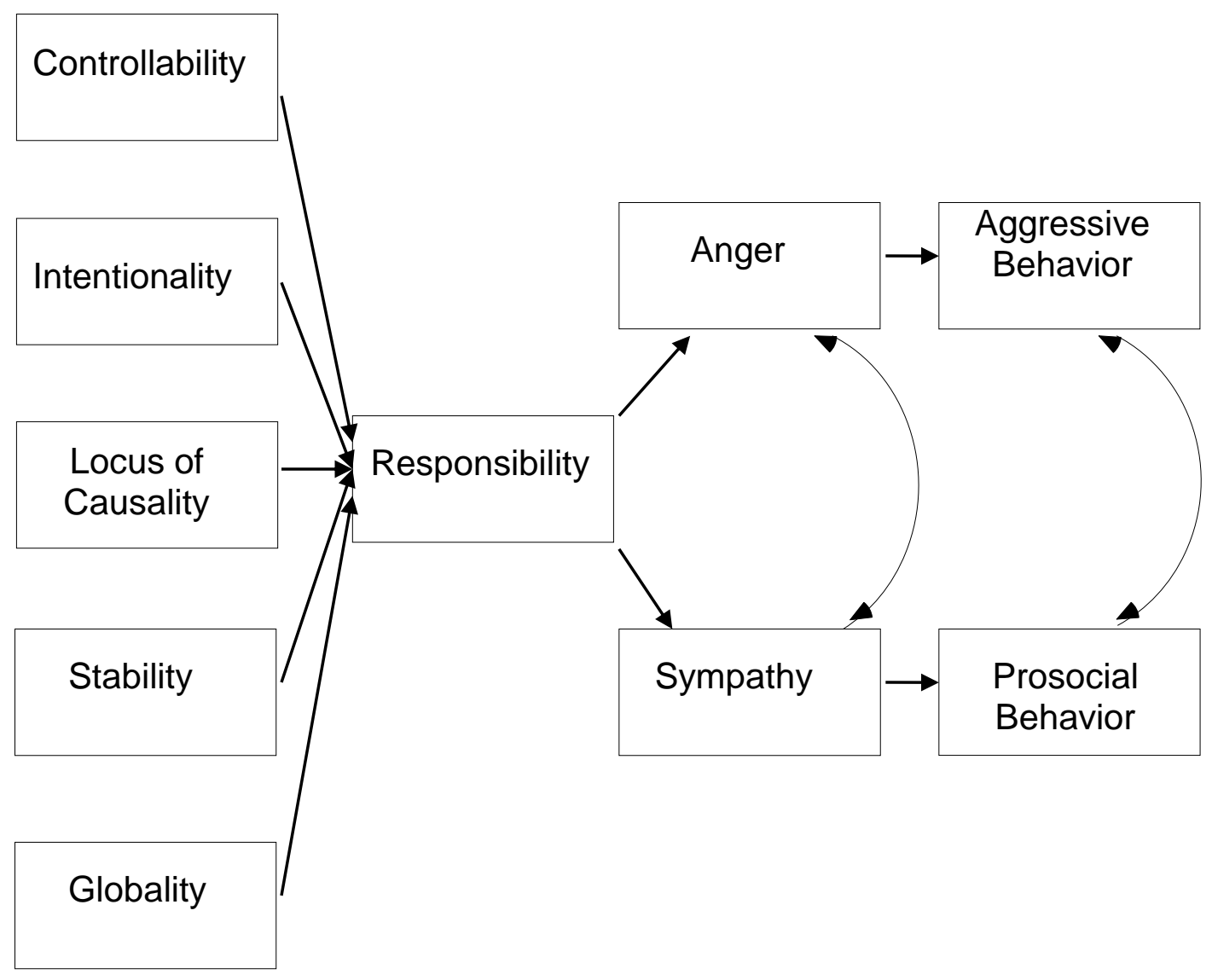

Figure 1. Weiner's attributional theory of social conduct. 


\section{Controllability $\square$ Intentionality}

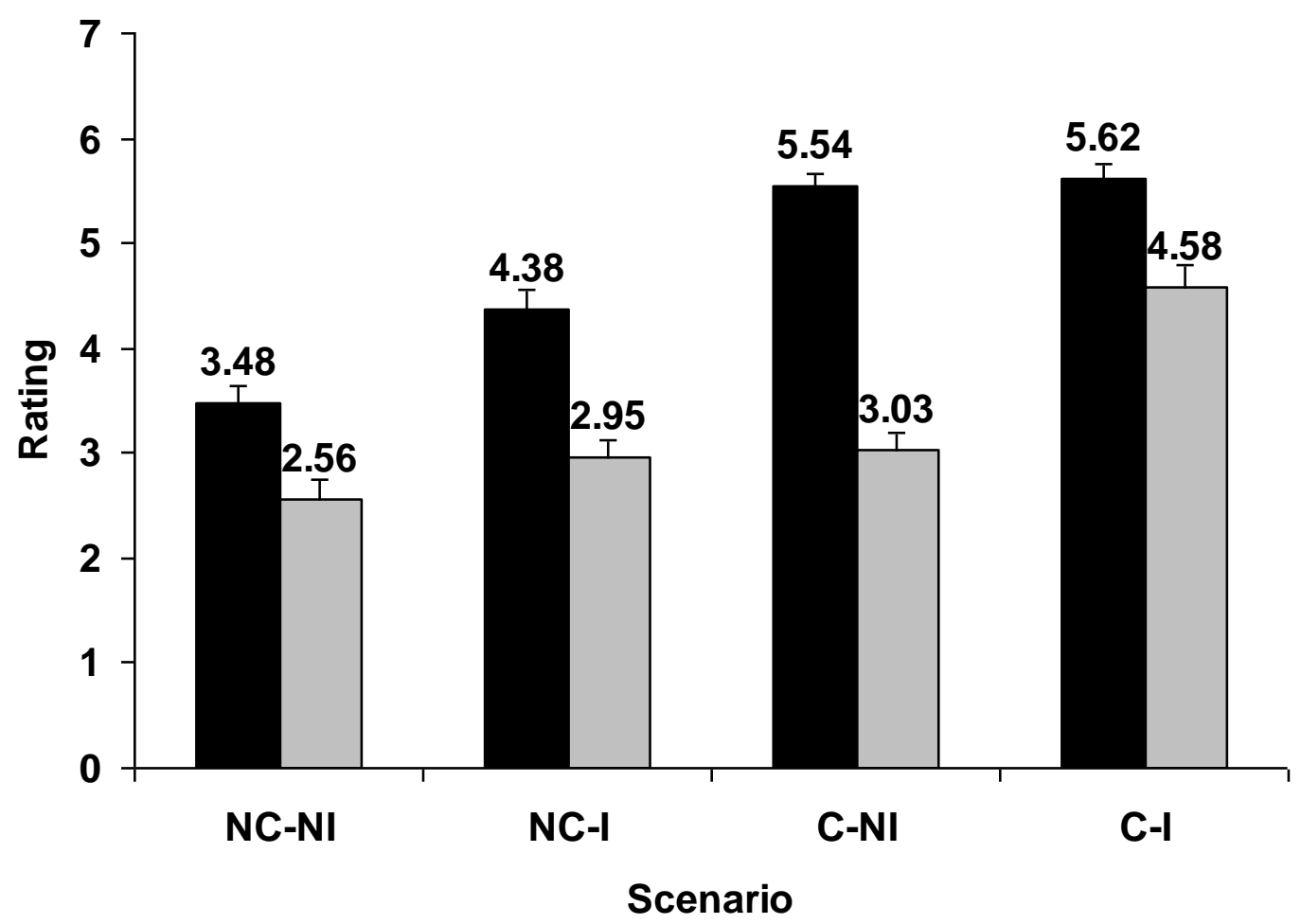

Figure 2. Study 1 mean controllability and intentionality scores as a function of group (NC-NI = no controllability - no intentionality, NC-I $=$ no controllability - intentionality, $\mathrm{C}-\mathrm{NI}=$ controllability - no intentionality, C-I = controllability - intentionality). Error bars represent standard error. 


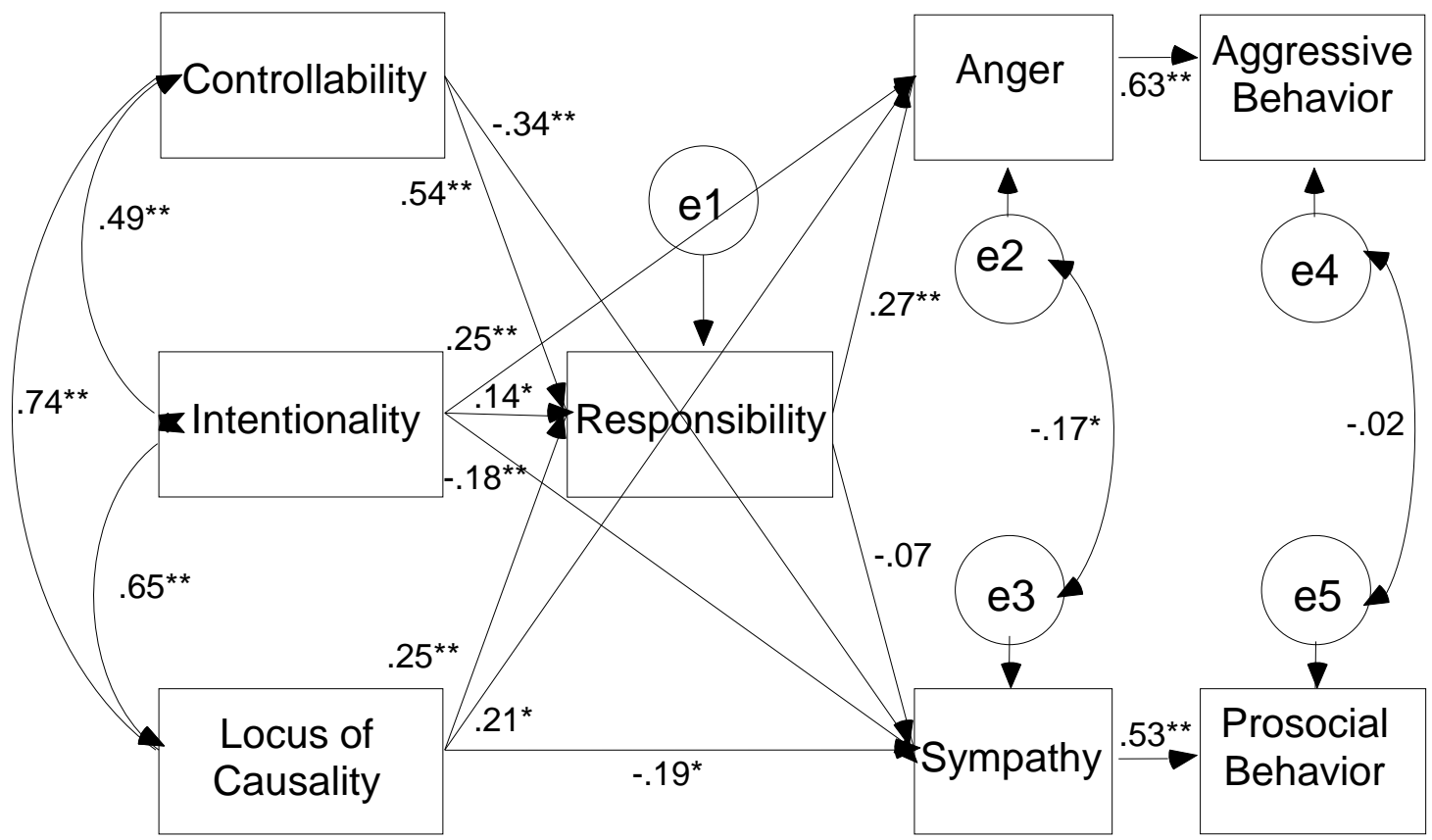

Figure 3. Study 1 attribution model. Standardized coefficients are reported $(N=214)$.

$* p<.05 . * * p<.01$. 


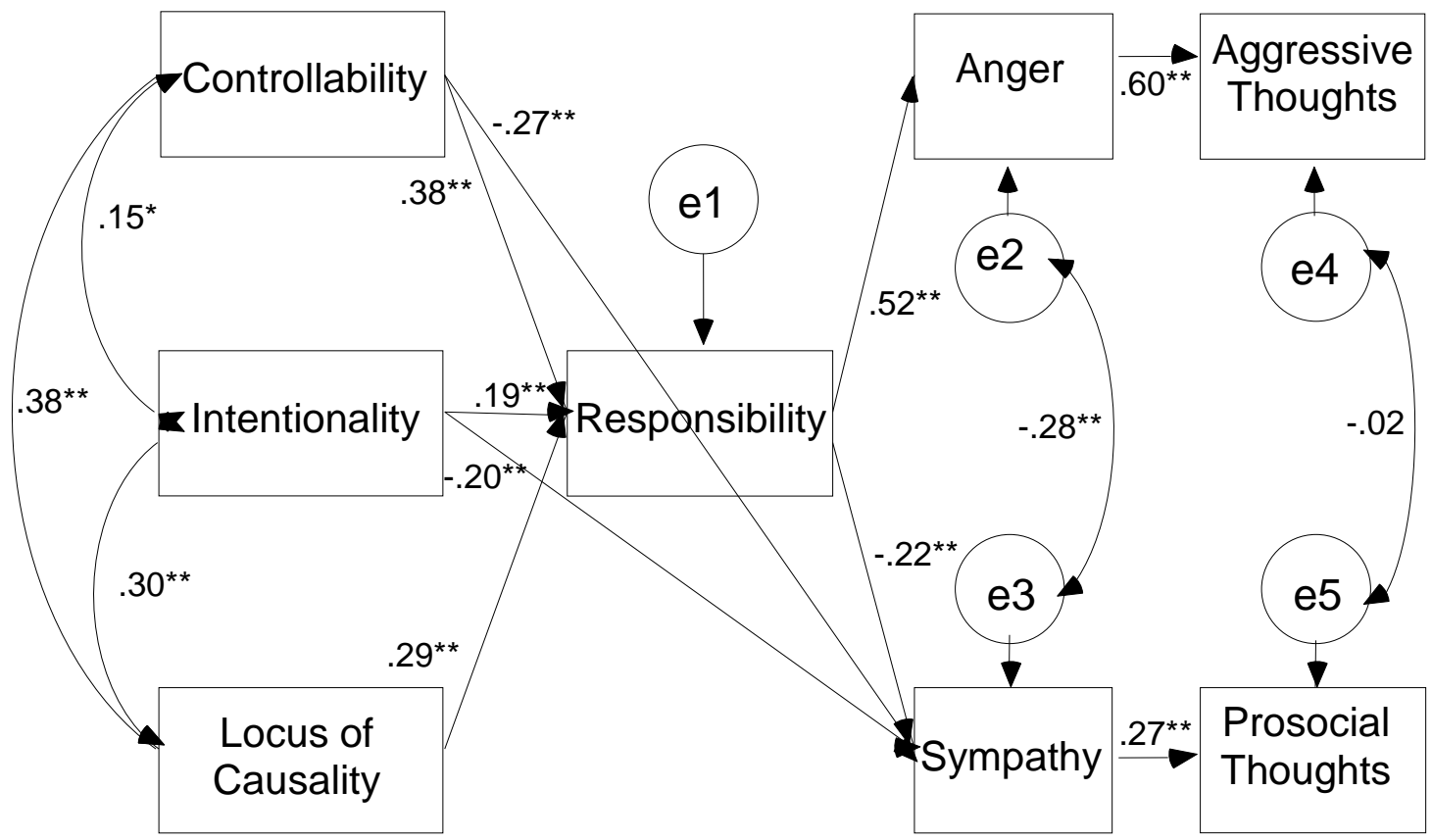

Figure 4. Study 2 "thoughts" attribution model. Standardized coefficients are reported $(N=194)$. $* p<.05 . * * p<.01$. 


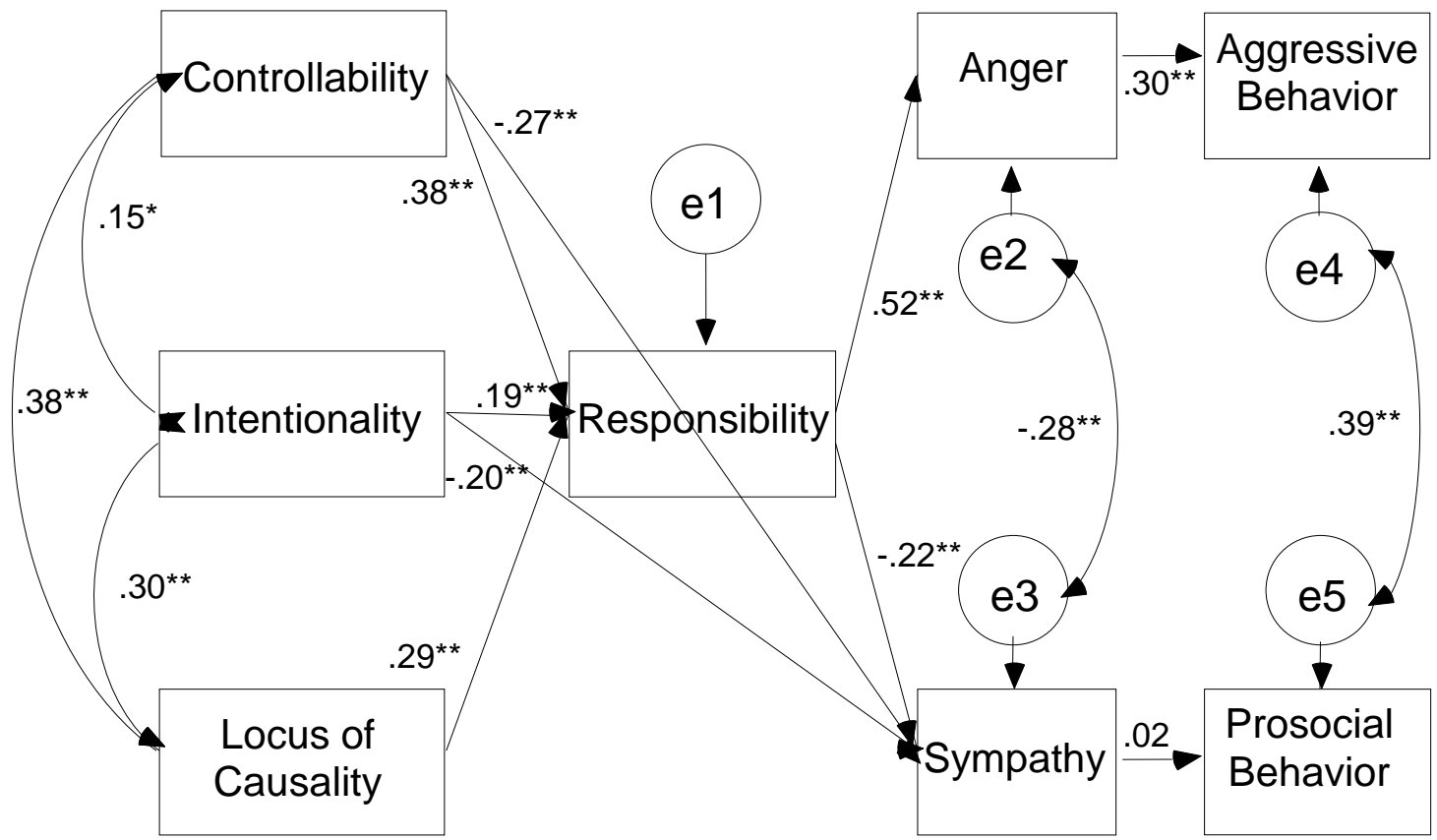

Figure 5. Study 2 "behaviors" attribution model. Standardized coefficients are reported $(N=$ 194). $* p<.05 . * * p<.01$. 